Louisiana State University

LSU Digital Commons

$1-1-1992$

\title{
Stress begins in kindergarten: A look at behavior during standardized testing
}

\author{
Pamela O. Fleege \\ University of North Texas \\ Rosalind Charlesworth \\ Louisiana State University \\ Diane C. Burts \\ Louisiana State University \\ Craig H. Hart \\ Brigham Young University
}

Follow this and additional works at: https://digitalcommons.Isu.edu/biosci_pubs

\section{Recommended Citation}

Fleege, P., Charlesworth, R., Burts, D., \& Hart, C. (1992). Stress begins in kindergarten: A look at behavior during standardized testing. Journal of Research in Childhood Education, 7(1), 20-26. https://doi.org/ $10.1080 / 02568549209594836$

This Article is brought to you for free and open access by the Department of Biological Sciences at LSU Digital Commons. It has been accepted for inclusion in Faculty Publications by an authorized administrator of LSU Digital Commons. For more information, please contact ir@lsu.edu. 
Louisiana State University LSU Digital Commons

1990

\section{Stress Begins in Kindergarten: A Look at Behavior During Standardized Testing.}

Pamela Owen Fleege

Louisiana State University and Agricultural \& Mechanical College

Follow this and additional works at: https://digitalcommons.lsu.edu/gradschool_disstheses

\section{Recommended Citation}

Fleege, Pamela Owen, "Stress Begins in Kindergarten: A Look at Behavior During Standardized Testing." (1990). LSU Historical Dissertations and Theses. 4912.

https://digitalcommons.lsu.edu/gradschool_disstheses/4912 


\section{INFORMATION TO USERS}

The most advanced technology has been used to photograph and reproduce this manuscript from the microfilm master. UMI films the text directly from the original or copy submitted. Thus, some thesis and dissertation copies are in typewriter face, while others may be from any type of computer printer.

The quality of this reproduction is dependent upon the quality of the copy submitted. Broken or indistinct print, colored or poor quality illustrations and photographs, print bleedthrough, substandard margins, and improper alignment can adversely affect reproduction.

In the unlikely event that the author did not send UMI a complete manuscript and there are missing pages, these will be noted. Also, if unauthorized copyright material had to be removed, a note will indicate the deletion.

Oversize materials (e.g., maps, drawings, charts) are reproduced by sectioning the original, beginning at the upper left-hand corner and continuing from left to right in equal sections with small overlaps. Each original is also photographed in one exposure and is included in reduced form at the back of the book.

Photographs included in the original manuscript have been reproduced xerographically in this copy. Higher quality 6" x 9" black and white photographic prints are available for any photographs or illustrations appearing in this copy for an additional charge. Contact UMI directly to order.

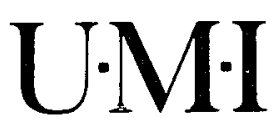



Order Number 9104130

Stress begins in kindergarten: A look at behavior during standardized testing

\author{
Fleege, Pamela Owen, Ph.D.
}

The Louisiana State University and Agricultural and Mechanical Col., 1990

Copyright (C1991 by Fleege, Pamela Owen. All rights reserved.

$\mathrm{U} \cdot \mathrm{M} \cdot \mathrm{I}$

300 N. Zeeb Rd.

Ann Arbor, MI 48106 


\section{,}


STRESS BEGINS IN KINDERGARTEN :

A LOOK AT BEHAVIOR DURING STANDARDIZED TESTING

A Dissertation

Submitted to the Graduate Faculty of the Louisiana State University and Agricultural and Mechanical College in partial fulfillment of the requirements for the degree of Doctor of Philosophy

in

The Department of Curriculum and Instruction

by

Pamela O. Fleege

B.S., University of Southern Mississippi, 1976

M.Ed., University of New Orleans, 1985

May 1990 


\section{ACKNOWLEDGMENTS}

I would like to express sincere appreciation and thanks to many people who have given me guidance, support, and encouragement throughout this study.

Special appreciation is extended to the following people who contributed to the completion of this dissertation:

Dr. Rosalind Charlesworth, Professor of Education, my committee chairman, for her guidance, time, friendship, and patience.

My committee members, Dr. Diane C. Burts, Associate Professor of Human Ecology, Dr. Craig H. Hart, Assistant Professor of Human Ecology, Dr. Evangeline McJamerson, Assistant Professor of Education, Dr. William F. Pinar, Professor of Education, and Dr. Nathan W. Gottfried, Professor of Psychology, for their valuable assistance and friendship.

Dr. Sandra Bifano, Assistant Professor of Education, for her assistance during the field work of this study.

The principals, teachers, and students, who must remain anonymous, for their participation in this study.

My friends, Jean Mosley and Carol Anderson, who gave me encouragement and support.

Carolyn M. Owen, my mother, for her love, support, and belief that this was possible.

And to my husband, Mark Fleege, and our children Rob 
and Ross, I give special thanks for their love, support, and sacrifice throughout my graduate studies. 
TABLE OF CONTENTS

I. Introduction

Statement of the Problem..............4

Purpose of the study.................

Research Questions..................

Definition of Terms................

Limitations.........................

Significance of the study.............

Design of the Dissertation............

II. Review of Literature

stress.......................... 10

Theoretical Framework................13

Developmentally Appropriate/Inappropriate

Practices..................... 18

Misuses of Tests and Test Scores..........22

III. Design \& Methods

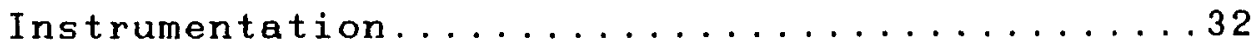

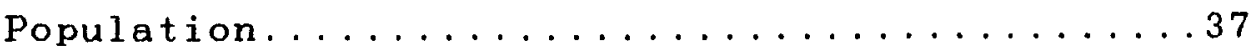

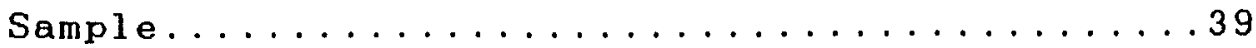

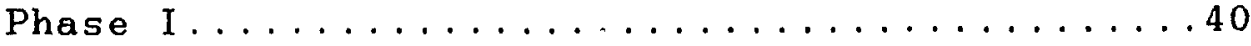

Phase II .......................

Phase III ......................

Phase IV...................... 47 


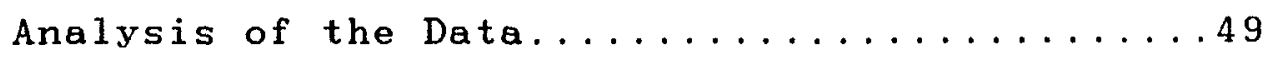

IV. Laurel Meadow Elementary

Setting...................... 51

Instructional Practices..............59

Principal's Impact on the Teacher

and students..................67

Standardized Achievement Testing............71

Reflections...................

V. Woodmere Elementary

Setting......................

Instructional Practices.............89

Principal's Impact on the Teacher

and students....................... 98

Standardized Achievement Testing...........104

Reflections........................

VI. Interpretation, Summary, Conclusions \& Future Research

Phase I, II, III, \& IV...............111

Laurel Meadow.....................113

Woodmere.......................... 118

Summary \& Conclusions................121

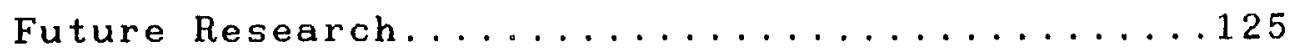

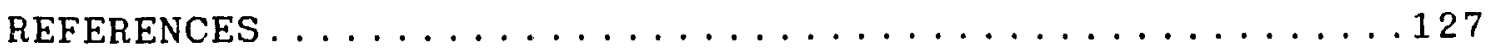




\section{APPENDICES}

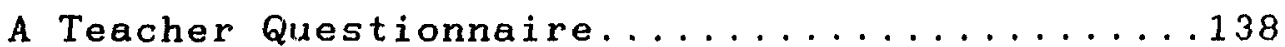

B Checklist for Rating Developmentally Appropriate Practice in Kindergarten Classrooms......146

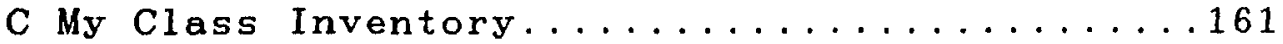

D Organizational Climate Description

Questionnaire - RS .................. 164

E Interpersonal Action Survey for Elementary...167

F Supervisor of Research \& Programming's Letter to Principals.................178

G Research Outline for Teachers...........180

H Research Outline for Parents............182

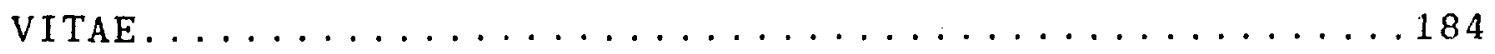




\section{ABSTRACT}

Children's behavior during standardized achievement testing was explored through a qualitative study of two kindergarten classrooms. The subjects were 36 kindergarten children (10 Black, 26 White; 17 males, 19 females). Data were collected through observations in the classrooms; interviews with children, teachers, and principals; and video taping of the children before, during, and after standardized achievement testing. Findings indicated an increase in behaviors reported to be stress related during the testing situation and a decrease in those behaviors following the testing period. Other frequently observed behaviors included copying and calling out answers during the administration of the test. In addition, the children frequently marked incorrect answers, although they could provide the correct answers orally. The attitude of the principals toward testing seemed to affect the testing situation. The principal who felt test scores were extremely important placed more emphasis on test performance. Children at this school engaged in more stress related behaviors than children in the school where the principal placed less emphasis on the importance of test scores. 


\section{CHAPTER I}

\section{INTRODUCTION}

The 1980's have witnessed a significant move in Early Childhood Education toward a more academic curriculum utilizing what professionals in the field call "developmentally inappropriate practices" (Elkind, 1988: Hatch, 1988; Smith \& Shepard, 1988). This trend is especially prevalent in kindergarten.

The move to developmentally inappropriate practice is viewed as possibly harmful by child development and early childhood education professionals. Noted psychologist, David Elkind (1981) says the potential harm to children lies in the pressure put on them which results in stress. Terms such as "hothousing" and "hurried" are being used to describe the children who are enrolled in developmentally inappropriate programs (Elkind, 1981; Gallagher \& Coche, 1987). These programs are considered inappropriate due to the children being pressured to acquire skills earlier than they are developmentally able (Elkind, 1981).

A recent study found that children attending a less developmentally appropriate kindergarten program exhibited more stress-related behaviors in the classroom than their counterparts in a more developmentally appropriate program (Burts, Hart, Charlesworth, \& Kirk, in press). Professionals 
in this area have called for an end to developmentally inappropriate instructional practices.

As a response to the outcry against developmentally inappropriate instructional practices, the National Association for the Education of Young Children (NAEYC) published a comprehensive document defining both appropriate and inappropriate practices in programs that serve children from birth through age eight (Bredekamp, 1987). This position statement represents the expertise of many child development experts and early childhood educators. It is based on the theoretical writings of Piaget (1947/50, 1952 . $1966 / 69,1969 / 70)$ and Montessori (1912/64). The writings of both Piaget and Montessori emphasize the role of the adult as that of a facilitator preparing the environment so the child can spend uninterrupted periods of time actively exploring concrete materials and interacting with peers and adults. While defining appropriate practices, the position statement also exemplifies inappropriate practices as being abstract, paper and pencil activities that are usually presented to large groups of children.

As a result of the NAEYC publication, Developmentally Appropriate Practice in Early Childhood Programs Serving Children From Birth Through Age 8 (Sredekamp, 1987), many researchers have begun to investigate issues related to appropriate and inappropriate practices. Some have focllsed on inappropriate practices as they relate to preservice 
teachers (Jensen \& Chevalier, 1988), parents (Hyson, 1988), kindergartners (Burts et al., in press; Hyson, 1988) and preschool children (Hirsh-Pasek \& Cone, 1989; Hyson, 1988).

The move toward more inappropriate practices in early childhood programs and the call for more accountability in schools has also resulted in an increase in the use of standardized tests. The use of standardized tests with young children has been criticized for the following reasons: (a) they are said to be culturally, ethnically/racially, and socioeconomically (SES) biased (Popham, 1988); (b) a narrow range of skills is assessed; (c) the child's development is viewed in a compartmentalized fashion; (d) they require inappropriate responses; and (e) frequently, their sçores are misused. For the above reasons, the most of ten criticized standardized test is the achievement test. Achievement tests require inappropriate responses, and the scores are often misused as the basis for educational decisions.

Although much has been written about the misuse of standardized tests and their inappropriateness for use with young children, there is little empirical data to support this assertion (Elkind, 1981; Meisels, 1987; Neill \& Medina, 1989). In light of this, the current literature suggests a need for investigation in the area of standardized testing and its effects on young children. 


\section{Statement of the Problem}

The problem is best defined by the questions: What effect does standardized testing have on kindergarten children's behavior? Is the behavior of these children different during standardized testing than during the course of everyday activities? If there is a difference in the children's behavior during testing, does the behavior return to the typical behavior pattern exhibited before testing? Also, if stress related behaviors are exhibited, what factors seem to increase or decrease the presence of these indicators?

Purpose of the Study

This study assessed the behaviors of kindergarten children during standardized achievement test taking. The primary objective of the research was to assess whether there was a change in the children's behavior during standardized achievement test-taking and what type of behaviors the children exhibited. If there was a change in the children's behavior during test taking, did the children's behavior return to what it had been prior to testing? A secondary focus of the study was to ascertain the children's perception of the testing situation and to look at how the social/emotional climate set by the teacher did or did not affect the children and their performance during the testing situation. 
Research Questions

This study endeavored to answer the following questions:

1. Do kindergarten children exhibit stress-related behaviors during standardized achievement testing?

2. What other types of behaviors do the children exhibit during standardized achievement test taking?

3. If the children exhibit behaviors said to be stress related during testing, does the behavior return to what it was prior to testing?

4. Do kindergarten children perceive standardized achievement testing as stressful?

5. How does the social/emotional. climate set by the teacher affect the children before, during, and after the testing situation?

\section{Definition of Terms}

For the purpose of this study, the following definitions were applied:

Developmentally Appropriate Practice - a safe, nurturing environment that promotes the physical, social, emotional, and cognitive development of children from birth to age eight while responding to the needs of families. Appropriate environments provide children challenges, support, and success based on individual 
needs, interests, and learning abilities. Those practices that require a child's active involvement using concrete materials. Evaluation would be through assessments that require the child to respond by pointing, verbalizing, or by reacting to an auditory stimuli. The assessments would consist of observations made during the course of the child's daily activities and samples of the child's work collected over a given period of time.

Developmentally Inappropriate Practice - those practices that are not based on the knowledge of how children learn and emphasize direct teaching to whole groups using mainly paper and pencil activities. The primary method of evaluation would be through group administered pencil and paper tests.

Developmentally Appropriate Classrooms - those two classrooms used in the study that used primarily developmentally appropriate practices. The teachers in those classrooms scored at least 1 SD below the mean on the inappropriate factor of the Teacher Questionnaire.

Mean ratings on the Checklist for Developmentally Appropriate Practice in Kindergarten Classrooms for the two teachers were 4.1 and 4.6 , with five being the most appropriate and one being the least appropriate. (Charlesworth, Hart, Burts, \& Hernandez, 1989). Stress-related Behaviors - those behaviors exhibited by the 
children which the literature defines as indicators of stress and taken from the Classroom Child Stress

Behavior Instrument developed by Burts et al. (in press), such as fatigue, feet shuffling, daydreaming, playing with clothes, grinding teeth, and complaining of feeling sick.

Kindergarten Children - those children enrolled in kindergarten during the 1988-89 school year regardless of chronological age.

\section{Limitations}

1. The findings of this study have situational applicability, that is contingent upon the particular school's environment. The transferability of this study to other settings is dependent upon the similarities between the contexts (Lincoln \& Guba, 1985, pp. 297-299).

2. The findings of this study must be interpreted with caution due to the unequal amounts of time spent in the two classrooms studied.

3. The racial composition and the socioeconomic levels of the children involved in the study are not reflective of the racial composition and socioeconomic levels of the schools system. The school system is comprised of $54 \%$ Black and $46 \%$ nonBlack, while the socioeconomic status covers the 
complete range of the Hollingshead Four Factor Index.

4. Due to the low response rate from teachers the discussion of school climate and principal leadership should be viewed cautiously.

\section{Significance of the Study}

Previous research has cited the need for empirical data to document the presence of stress during developmentally inappropriate practices (Burts et al., in press). This study focused on the inappropriate practice of standardized achievement testing. The study assessed behavior before, during, and after standardized achievement testing for signs of stress in kindergarten children. The findings which emerged from this research will contribute to the existing body of knowledge concerned with inappropriate practice and its relationship to stress in young children.

\section{Design of the Dissertation}

The dissertation is presented in six major chapters. Chapter One includes an introduction which provides an overview for the need for this research endeavor, the statement of the problem, the purpose of the study, pertinent research questions, limitations of the research, and the significance of the study. Chapter Two presents a literature review to provide an appropriate background for 
this study. Chapter Three includes the design and methods of the field study. The findings are discussed in chapters Four and Five. The two classrooms are described in detail so that the reader will become a part of the classrooms to get a sense of the children's everyday life, their personalities, and their reactions to the testing situation. In addition, the reader will be made aware of the impact teachers and principals have on students. The final chapter contains the implications, summary, conclusions, and future directions for research. 


\section{CHAPTER I I}

\section{REVIEW OF LITERATURE}

The review of literature will cover the areas of stress, theoretical framework, developmentally appropriate and inappropriate instructional practices, and misuse of tests and test scores. These areas will be discussed separately and in terms of how they relate to each other.

\section{Stress}

In recent years, there has been a reported increase in the use of more academically orientated activities with young children (Hatch \& Freeman, 1988; Shepard \& Smith, 1988). These activities consist mainly of highly structured pencil and paper tasks. Terms such as "miseducation", "hothousing", and "hurried" have become associated with children enrolled in such programs (Elkind, 1981, 1989; Gallagher \& Coche, 1987). These predominately academic and highly pressured practices are considered by many in the field to be inappropriate for use with young children. In response to this trend, there has been a national outcry for a return to more appropriate teaching practices and materials (Bredekamp, 1987; Charlesworth, 1985, 1989; Kamii, 1985; Williams \& Kamii, 1986). According to experts in the field of child development and early childhood education, 
these types of activities could result in an increase in stress-related behaviors due to increased academic pressure and inability to complete the tasks with ease and understanding (Elkind, 1986; Isenberg, 1987).

When looking at the literature, one finds there is no consensus concerning the definition of stress. Selye (1976, p. 1) defines stress as the "response of the body to any demand" while Honig (1986a, p. 51) defines it as "a nonspecific response of the body to any demand that exceeds the person's ability to cope, as a person-environment relationship that threatens or taxes personal resources, and as a mental state in response to strains or daily hassles." Stress can arise from internal or external factors and varies from child to child. What one child finds as stressful may not affect another in the same negative way. According to Rutter (1979a, 1979b) several things can affect how a child copes with stress. Rutter lists a multiplicity of stressors-- change in circumstances, factors in the family (e.g., positive parental relationships, extended family), factors in the child (e.g., gender, temperament, genetic background), and factors outside the home (e.g., neighborhood, quality of school)-as affecting the ability to cope with stress. To so, a child may try a variety of strategies such as ignoring, compromising, or changing activities. The child may also choose inappropriate behaviors to try and cope with the stress such as crying, 
aggressive acts, or pants wetting.

The children of today are exposed to numerous stressors in their lives (McCracken, 1986; Swick, 1987). These stressors may be attributed to several causes: (1) parents are under more stress, (2) there is more pressure to succeed in the eyes of parents, (3) there is an increase in competition in the classroom, (4) and there is greater competition in outside activities (e.g., athletics, dance) (O'Brien, 1988). According to Rutter (1979b) the danger for children lies in the cumulative stress over a period of time. Some of the long-term effects of stress as predicted by Elkind (1981) are lack of motivation, lack of selfdirection, more obsessive behavior, more psychosomatic symptoms, juvenile delinquency, and possibly suicide. If these predictions are true, then it is imperative that stress be reduced.

Little research has been done in the area of early childhood development which documents the relationship between stressors and academic and social behavior. However, Swick (1987) stated that when the classroom was viewed from a time, space, and human relations standpoint that children exhibited stress-related behaviors in response to certain situations. Some of the behaviors exhibited are as follows: fatigue, attention seeking behaviors, feet shuffling, paper rattling, hoarding of toys, fear, and insecurity. Other stress-related reactions cited in the literature include 
daydreaming, frequent temper tantrums, punishing one's self, tatting or jeering at other children, grinding teeth, playing with clothes, stuttering, refusing to talk, withdrawing from the group, and/or complaining of feeling sick (Honig, 1986b). In a study conducted by Burts et al. (in press), children who had attended a more developmentally inappropriate kindergarten program exhibited more stressrelated behaviors than did children who attended a more developmentally appropriate program. Males also exhibited more stress-related behavior than did females. The authors warned that these findings must be looked at cautiously, however, because of the small number of subjects.

Bentley (1988) also found there was more stress in less developmentally appropriate half-day kindergarten programs than in the more developmentally appropriate half-day kindergartens. Since children are exposed to more and more stress outside of school, it seems imperative that the classroom environments which are more and less stress producing be identified and that educators modify instruction in order to lower the stress level.

Theoretical Framework

The theoretical basis for the study was provided by Piaget's Cognitive Developmental Theory (Piaget \& Inhelder, 1966/69). He believed that children actively construct their own knowledge. They are not just passive creatures for whom the environment decides what is learned. Knowledge is 
constructed through interactions between a child's mental structures (which Piaget called schemas) and the environment.

As a child interacts with his environment, information is taken in and either fitted into the existing schema through a process called assimilation or placed in new schemes developed to handle it through a process called accommodation. When new information must be incorporated, a sense of disequilibrium occurs. In order to reach equilibrium the person engages in assimilation and/or accommodation and thus expands and refines his/her schemes. Maturation, physical experience, and social interactions are all things that can affect the development of a child. Maturation affects a child's development because an older child will be more likely to have more schemes and act in a more coordinated way. The nervous system controls the degree of potentialities available at any given time. Simultaneously the environment has an interactive effect in that the more physical experience a child has with objects, the more likely he/she is to develop understandings related to these objects. According to Piaget, a child must manipulate objects before he/she can develop a logical understanding. Social interaction is also important to the development of a child. Through interaction with others, a child learns other viewpoints and gradually moves toward being objective. A child also learns information that would 
be considered "social knowledge." Social knowledge would include such things as customs or labels.

The interactions between and among the above mentioned factors influence a child's development. These interactions are called equilibration. Equilibration is a constant interaction between a child's mind and reality. As a child engages in this process, he/she either assimilates information into existing schemes or accommodates the information by developing new schemes. Equilibration is a self-regulation process through which children actively construct their own knowledge.

Throughout his years of observing children. Piaget saw that children of 1 ike ages of ten responded in ways which were very similar. From these observations he developed a stage approach to looking at children's cognitive development. He believed that the stages were invariant and universal. Each stage is derived from previous stages that are transformed into a new one.

Piaget's four stages of children's thinking are sensori-motor, preoperational, concrete operational, and formal operational. All children proceed through these stages but not necessarily at the same time. The age ranges are approximate, thus reflecting that there is not an exact age at which each behavior appears.

The sensori-motor period is roughly considered birth through 2 years of age. This stage is characterized by the 
child's interaction with the world through the perceptual and motor systems. Through overt actions the child learns about properties of objects and relations among them. Cognitive structures become more tightly organized and the child is able to coordinate schemes and apply them to new situations. According to Piaget (1952) later cognitive structures will evolve from these behavioral structures. Behavior becomes intentional over time and self is gradually differentiated from the environment.

The preoperational stage is associated with ages 2 to 7. This stage is characterized as one of egocentrism, rigidity of thought, semiological reasoning, and limited social cognition. Piaget divides the preoperational stage into two phases: the preconceptual period (from about 2 to 4 years of age) and the intuitive period (from about 4 to 7 years of age). During the preconceptual period children begin to verbally label objects, events, activities and use one object for another. Their reasoning ability is rather primitive and they tend to infer causal relationships between events even when there is none. The preconceptual child is egocentric and has trouble taking another's point of view. Play serves as a child's way to refine certain physical schemata and to combine these actions in new and more complex ways.

Children in the intuitive period are less egocentric and more proficient at using symbols in their reasoning. 
However, a child's thinking at this stage is still not at a level that will allow her to be compared with an adult's reasoning ability. Thinking in this period is characterized by the child comprehension of an object centering on its most salient perceptual feature.

The behavioral schemas developed during the sensorimotor stage now become mental schemas because the child is capable of representational thought. A preopertational child is unable to take another's conceptual perspective or mentally reverse a series of events. This age is characterized by play in terms of symbolic play, social games, and games of construction. As Labinowicz (1980) stated, for children in the pre-operational stage, play is reality. Most children in kindergarten classes can be categorized as being in Piaget's preoperational stage. The majority of the children would be in the intuitive phase while some would be in the preconceptual phase.

The third stage of Piaget's theory is called concrete operational and is associated with children ages 7 to 11 years of age. Thought is now decentralized and the child is now capable of mentally reversing an action. A logical system of thought in relation to objects appears, egocentrism decreases, and the child increasingly becomes able to see another's point of view.

In the formal operational stage a child is able to think beyond concrete reality. This stage is commonly 
associated with children ages 11 to 15 years old. Children in this stage are capable of abstract reasoning and no longer require concrete objects to manipulate.

Instructional practices associated with children in the preoperational stage would be those that allow the children to actively interact with objects. Children would be asked to verbalize about what they were doing and about the properties of the objects. Play would be the method of instruction. These practices would be used because children in this stage are not capable of abstract reasoning and do not possess the fine motor skills to engage in a lot of written work. Kindergarten children 5- and 6-years of age would be categorized as being in the preoperational stage. Children in this stage would be assessed in natural settings using observations and work samples to document their progress.

\section{Developmentally Appropriate/Inappropriate Practices}

Developmentally Appropriate Practice in Early Childhood Programs Serving Children From Birth to Age 8 (Bredekamp, 1987) is a comprehensive document published by the National Association for the Education of Young Children (NAEYC) to define the types of practices and materials to be used with young children. This document was developed using the expert knowledge of the foremost authorities in the fields of child development and early childhood education. The theoretical 
framework is drawn from the writings of Piaget (1947/50. $1952,1969 / 70)$ and Montessori (1912/64). Their work emphasized the role of the teacher as that of a facilitator who prepares the environment so that children can spend periods of uninterrupted time actively exploring concrete materials. Appropriate practice also encourages interaction of peers and that of child with adult.

Developmentally appropriate practice is based upon activities that are both age appropriate and individually appropriate. Classrooms that are considered developmentaljy appropriate are those that are child centered, use the concrete hands-on approach, and small group and individual instruction. Emphasis is placed on the development of the child's self-esteem through appropriate guidance which demonstrates respect for the child. In a developmentally appropriate classroom authentic assessment in the naturalistic setting (e.g. observations, work samples, portfolios, video tapes) would be used to document a child's progress.

In contrast, a developmentally inappropriate classroom would feature many paper and pencil activities, the teaching of isolated skills, and much whole group instruction. Assessment would rely mainly on the use of end-of-thechapter or book tests provided by the textbook publishing companies, isolated skill tests, and standardized achievement tests. These types of assessments are 
considered inappropriate because they require the children to make inappropriate responses. Children in the preoperational stage of ten do not possess the fine motor ability to color in small circles. Unacceptable guidance strategies found in these classrooms could possibly include screaming in anger; neglect, inflicting physical or emotional pain; criticism of the child's person or family by ridiculing, blaming, teasing, insulting, namecalling or threatening; or using frightening or humiliating punishment (Bredekamp, 1987). Since the emotional climate of the classroom is said to have a bearing on student achievement, inappropriate guidance strategies may negatively affect children. According to Brophy (1986), empirical studies consistently find negative relationships between achievement gain and measures of teacher criticism, threat, ridicule, or punishment of students. In contrast, classrooms that produce high achievement gains are described as pleasant and convivial (Berliner \& Tikunoff, 1977).

The stress producers that Swick (1987) identified are equivalent to those described in the developmentally inappropriate practices section of the NAEYC position statement (Bredekamp, 1987) while a low stress environment as described by Swick seems to be congruent with those practices described as being developmentally appropriate. A developmentally appropriate classroom would also be one identified as having low stress because it encourages 
experiences that meet the needs of individual children, and promote self-esteem, active exploration, and concrete experiences.

Much has been written about the damaging effects of inappropriate curricula and teaching practices (Dickinson \& Snow, 1987; Elkind, 1986; Gallagher \& Coche, 1987; Isenberg, 1987; Shepard \& Smith, 1988; Short, 1988; Sige1, 1987;

Willert \& Kamii, 1985), but little research evidence have been published to support these claims. There is some support to the claims of damaging effects from the Burts et al. (in press) and Bentley (1988). Their studies found that children in less developmentally appropriate classrooms exhibited more stress than did children in more developmentally appropriate classrooms. Schweinhart, Weikart, \& Larner (1986) also found that direct instruction may be related to poor social performance. However, the conclusions drawn from this study have been subjected to much criticism (Bereiter, 1986; Gersten, 1986; Karweit, 1988 ) and must also be viewed cautiously.

One inappropriate practice that seems to abound in most schools is the use of standardized tests. Used in prekindergarten through twelfth grade, this type of test comes in many forms, the most common being end-of-the-chapter or book tests, achievement tests, and I.Q. tests. 
Misuse of Tests and Test Scores

Standardized tests are defined by NAEYC as "an instrument composed of empirically selected items that has definite instructions for use, adequate determined norms, and data on reliability and validity" (NAEYC, 1988). These tests can be either norm- or criterion-referenced.

Standardized tests that are used most of ten with young children are readiness, developmental screening, and achievement tests. NAEYC (1988) has defined these tests as follows:

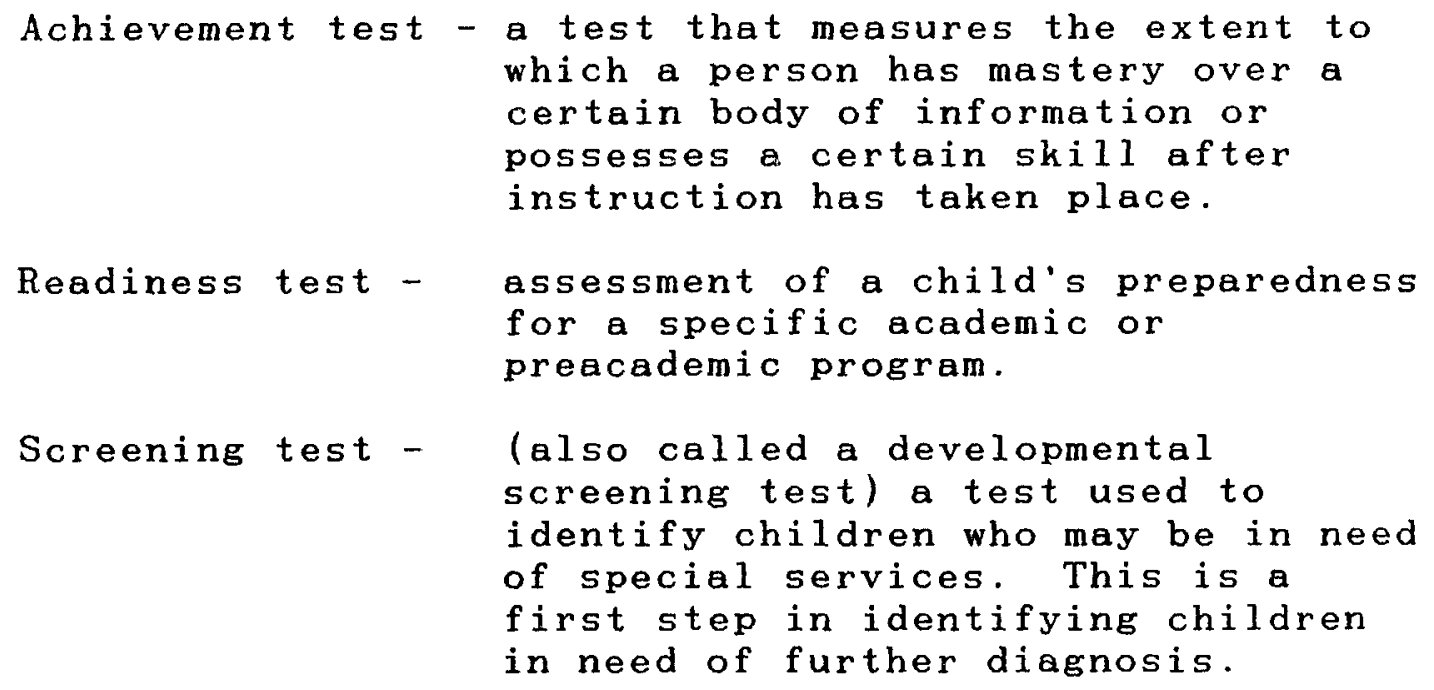
which a person has mastery over a certain body of information or possesses a certain skill after instruction has taken place.

Readiness test - assessment of a child's preparedness for a specific academic or preacademic program.

Screening test - (also called a developmental screening test) a test used to identify children who may be in need of special services. This is a first step in identifying children in need of further diagnosis.

Many standardized tests have been criticized as being culturally, ethnically/racially, and socioeconomically (SES) biased (Laosa, 1977a, 1977b; Popham, 1988; Travers, 1982). This may mean for example that the tests ask questions that are not familiar to every segment of the population. Most frequently tests are criticized for using norming populations that are predominately white and middle class. These tests are said to be biased because minority children 
and children from low socioeconomic backgrounds tend to score less well than white middle class children (Laosa, 1977a; 1977b; NAEYC, 1988; Popham, 1988; Torrance, 1974 ; Travers, 1982).

Due to the push for academics and the decline of confidence in the schools, there has been a demand for accountability. The response to this demand has been an increase in the use of tests (Perrone, 1981). With their jobs on the line, many teachers have responded by teaching to the test. Piaget warned about this misuse of testing in his book Science of Education and the Psychology of the Child (1970). He felt there was the danger of the test becoming the curriculum. This view has received more and more support in the last few years (Haney \& Madaus, 1989; Madaus, 1988; Meisels, 1989; Olson, 1987). Piaget also pointed out that the tests do not show how children arrive at their answers. In his opinion, the process was more important than the product.

A major criticism of standardized tests has been the inappropriate use of the instruments. The instruments may be used for purposes for which they are not designed. An example would be using the Metropolitan Readiness Test to screen for language problems. A readiness test should never be used to screen for possible problem areas. Only a developmental screening test should be used to ascertain if a child needs further diagnostic assessment. A readiness 
test should never be used as a screening device. Before selecting an instrument, the purpose for which it will be used must be clearly defined. For a test to be valid and reliable, it must be used for the purpose for which it was developed and with the type of population on which it was normed. No test is valid for all purposes (Farr \& Carey, 1986). An instrument should not be used if the reliability or validity data is missing or unclear.

Another criticism of standardized tests is the inappropriate use of their scores. The scores from these tests have been used to place children in developmental programs, retain them in present grade, and make decisions regarding entrance into school (Bredekamp \& Shepard, 1989; Charlesworth, 1989; Meisels, 1987, 1989; Neill \& Medina, 1989). The controversy seems to center on children not "being ready" for kindergarten. According to Charlesworth (1989), it is not that the children are not ready for school; the school is not ready for the children. Children are not being viewed as individuals with individual wants and needs. Shepard \& Smith (1988) define the problem as kindergarten attendance being universal and first grade teachers assuming that all children have a common set of prerequisites. The pressure is then put on the first grade teachers who, in turn, put pressure on the kindergarten teachers. Instead of fitting the curriculum to the child, there is an effort to fit the child to the curriculum 
(Charlesworth, 1989).

Attempts are made to fit the child to the curriculum by raising the kindergarten entrance age or keeping the child home an extra year. For many years a child had to be 5 by December 31 to enter kindergarten. Now many school districts have moved the date back to September and October. Indiana is even going to a June 1st entrance age in 1992 (The Early Childhood Advocate, 1989). The developmental level of the children as they appear on standardized tests has been used as support for moving back the age of school entrance. Advocates of this decision are quick to explain that this will give the younger children an extra year to mature because they are the ones who are most likely to have trouble in school and are the ones most frequently retained. Teachers and administrators who hold this view of development are said to be nativitists. They believe the development of school readiness is an internal, organismic process unrelated to environment (Miller, 1983; Smith \& Shepard, 1988). In their opinion, the only way to help a child who is developmentally young is to give him more time to mature.

Research shows, however, that being a younger member of the class is not necessarily detrimental. Initially, the older children might perform better academically, but by the end of third grade no significant difference is found (Durkin, 1987; Shepard \& Smith, 1997, 1988; Smith \& Shepard, 
1987, 1988). What is detrimental about being one of the youngest in the class is the teacher's attitude. In several studies, teachers who held a nativist view of development saw the younger children as academically and socially less mature than their older classmates and were more likely to retain or refer the children for special services (Connell. 1987 ; Gredler, 1978; Morado, 1987; Shepard \& Smith, 1986 ; Walsh, 1989). What many fail to see is that no matter what cut of date is used for entrance, there will always be a group of "younger" children in every class. At the moment, school systems are worried about the children whose birthdates are in the fall. If they are eliminated, then the children with summer birthdates will be the "young" children and they will be compared to the children who are older. The problem then becomes a vicious circle with no end in sight. Another inappropriate use of instruments and test scores has been there use in placing children in transition classes. Readiness and developmental screening tests art being used to identify children who are considered developmentally young in order to place them in what has been referred to as a transition class. The transition class is one that, depending on the school, a child enters prior to kindergarten or after kindergarten. Either way, the child would spend two years in school before entering first grade. Many teachers and administrators like this alternative because they say it gives the child the time he needs to 
develop. They also insist that it is not like being retained because no stigma is attached to the child. However, to the child, putting him in a transition class or retaining him/her in the same grade makes no difference. The child is fully aware that he/she is not continuing with his/her peers. The child then feels a sense of failure (Shepard \& Smith, 1988).

Gredler (1984), in his review of research on transition rooms, found that transition room children either did not perform as well or, at best, performed at the same level of achievement as transition room eligible children who were placed in regular classrooms. Children placed in the transition classes showed a loss of self-concept when compared to their counterparts placed in regular classrooms. Shepard \& Smith (1988) confirmed Gredler's academic findings. However, when the teachers' ratings were tabulated they found no difference in the self-concept of transition students and those who had been placed in the regular classroom. On the other hand, when parents rated their children on self-concept, they noted a loss of self-esteem. Comments from parents related children's experiences such as being teased by classmates, feeling like a failure. and being bored. Shepard \& Smith (1988) concluded that the children were aware they were not progressing as their peers.

Another inappropriate use of test scores is retention. 
Achievement test scores are commonly an important element in such decisions. This practice continues even though research indicates that children who are retained do less well academically than children who are passed to the next grade. They also tend to have lower self-esteem (Connel1, 1987; Gredler, 1978; Shepard \& Smith, 1987).

In addition to criticisms of standardized tests in general, a specific criticism of standardized achievement tests is that they assess a narrow range of information and view a child's progress in a compartmentalized fashion (Cryan, 1986; Devaney, 1974; Mendelson \& Atlas, 1973). Skinner (1968, p. 235) stated, "What is taught of ten tends to be simply what can be measured by tests and examinations. Behavior which does not easily submit to measurement is neglected because it would not impress accrediting agencies or others who judge an institution."

Achievement tests are also criticized as being biased towards minorities. According to Choen (1969), school settings and achievement tests focus on the analytic mode of selecting and organizing information, and many low SES children do not select or organize information in this manner. Therefore, the tests would be considered biased for this segment of the population.

In addition to being biased, many of the achievement tests now in use were constructed using research done 20 30 years ago. These tests do not reflect recent research in 
the areas of 1 iteracy and mathematics and the resultant new trends in instruction. However, North Carolina is keeping abreast of the current research and is now offering alternative assessments in the areas of communication and mathematics. These alternatives use samples of the children's work and observations conducted over time to document a child's progress.

Another criticism of achievement tests is that they do not match the curriculum used in school or the current teaching methods (Wortham, 1990). Bracey (1986), quoting an article in Captrends, indicated the best match between achievement tests and any given textbook was $50 \%$. In his opinion, the tests underestimate children's learning. This findirg is supported by studies which indicate that standardized tests do not correspond to the curriculum being taught (Flood, 1987; Glicking \& Thompson, 1985; Hiebert, 1988; Teale, Hiebert, \& Chittenden, 1987; "Testing", 1988 ; Valencia \& Pearson, 1987).

Achievement tests are considered to be developmentally inappropriate because they require children to make inappropriate responses. Wodtke, Harper, Schommer, \& Brunelli (in press) reported that the kindergarten children they observed, copied and called out answers while taking the California Achievement Test. A test that requires a child to respond mainly in a motoric fashion (such as pointing), to verbalize, or to react to auditory stimuli 
would be considered one that asked for developmentally appropriate responses. Paper and pencil responses should only be used to check perceptual-motor functioning (Charlesworth, 1985). To obtain responses, the examiner should use concrete materials and pictures. Achievement tests require the child to respond to questions by marking an $X$ on a picture or coloring in small circles that can be graded mechanically. Using this method to respond to questions would create a hardship for children who do not possess the fine motor skills that would allow them to respond. The test would not be assessing whether the child knew the correct response but whether he/she could color within the predetermined circles or make an $X$.

The present study was undertaken due to the dearth empirical evidence in the literature relative to the relationship between stress and standardized testing of young children. It was also undertaken, in part, because of the researcher's personal experiences in the classroom and reports from colleagues of events that took place in the classroom during standardized testing situations. This study examined kindergartners' behaviors during standardized achievement testing, focusing on stress-related behaviors. 
CHAPTER I I

DESIGN \& METHODS

The purpose of this study was to investigate kindergarten students' behavior during standardized achievement testing as compared with everyday classroom behavior. Also compared was student behavior during standardized achievement testing in two classrooms that were varied in degree of developmental appropriateness. Jean Piaget's Cognitive Developmental Theory (Piaget \& Inhelder. $1966 / 69)$ served as the theoretical structure for the study. The study unfolded in four phases. Phases I and II followed an empirical design to collect and analyze quantitative data related to the teachers' espoused theory and actual practice. Phase II consisted of gaining access to two classrooms in which naturalistic observations were conducted. Phase IV followed the natural paradigm in which two case studies were developed to provide "thick" descriptive data concerning the level of stress during the standardized achievement testing situation and factors which affected that level.

The present study was based on the supposition that observed stress behaviors would increase in frequency during developmentally inappropriate assessment experiences. 
Instrumentation

Two of the instruments used in this study, the Teacher Questionnaire and the Checklist for Rating Developmentally Appropriate Practice in Kindergarten Classrooms

(Charlesworth, Hart, Burts, \& Hernandez, 1989) were designed specifically to identify more and less developmentally appropriate classrooms. Information from these instruments was used to identify the two classrooms in this study that were part of a more extensive study conducted by Burts, Hart, \& Charlesworth (1990).

The Teacher Questionnaire was constructed using the position statement of the National Association for the Education of Young Children on developmentally appropriate practice for 5-to 8-year-olds (1987). The instrument consists of three parts. The first section consists of demographic information, education, and teaching experience. Respondents are asked to rank order the following relative to the degree of influence each has on their planning and implementation of instruction: parents, parish or school system policy, principal, teacher (themselves), state regulation, and other teachers.

Two subscales compose the majority of the questionnaire. They are the Teacher Beliefs Scale (TBS) and the Instructional Activities Scale (IAS). The Teacher Beliefs Scale is a 37-item paper and pencil measure designed to ascertain a teacher's philosophy regarding 
developmentally appropriate practices outlined by NAEYC. The teachers are asked to rate each item on a 5-point likert scale as to how important they feel each is in their classroom. The choices range from "Not Important At All" to "Extremely Important". The following is an example of the items contained in the scale: "As an evaluation technique in the kindergarten program, standardized tests are (see Appendix A)

A factor analysis using the principle components method was conducted. From this analysis six factors emerged. The factors are: (a) Developmentally Inappropriate Activities \& Materials, (b) Developmentally Appropriate Social, (c) Appropriate Individualization, (d) Appropriate Literacy Activities, (e) Appropriate Integrated Curriculum Beliefs, and (f) Inappropriate Structure. Subscale reliability as assessed by Cronbach's alpha ranged from .58 to .84 on the six factors.

The Instructional Activities Scale was used to assess the teacher's perception of the amount of time children spend in various classroom activities. The scale contains 34 items and uses a 5-point scale ranging from "Never or Almost Never (less than monthly)" to "Very Often (1-3 times daily)." Teachers are asked to mark the scale for each item such as: "circling, underlining, and/or marking on items on worksheets." (See Appendix A)

After the principle components analysis was conducted, 
seven factors emerged. They are: (a) Appropriate Activities, (b) Inappropriate Literacy Activities, (c) Inappropriate Learning, (d) Appropriate Creative Exploratory Learning, (e) Appropriate Integrated Curriculum Practices, (f) Inappropriate Management and Guidance Techniques, and (g) Inappropriate Transitional Activities. Subscale reliability as assessed by Cronbach's alpha ranged from .56 to .79 on the seven components.

The Checklist for Rating Developmentally Appropriate Practice In Kindergarten Classrooms was also developed based on the NAEYC guidelines for 5-8 year olds (NAEYC, 1987) and consists of 28 items that are related to but not matched one-to-one with those items included on the teacher questionnaire (see Appendix B). The items are divided into eight categories: (a) Curriculum Goals, (b) Teaching Strategies, (c) Integrated Curriculum, (d) Guidance of Social-Emotional Development, (e) Motivation, (f) ParentTeacher Relations, (g) Evaluation, and (h) Transitions. The observer uses a 5-point Likert scale to rate each item with the most appropriate practice descriptors 1 isted under 5 and the least appropriate practice descriptors listed under 1. Five was marked if the item observed was close to $100 \%$ appropriate, 4 for more appropriate than inappropriate, 3 for equally appropriate and inappropriate, 2 for more inappropriate than appropriate, and 1 for close to $100 \%$ inappropriate. 
The My Class Inventory (MCI) as adapted for administration by Fuqua (1986), was administered to the children in this study (see Appendix C). The MCI is a modified version of the Learning Environment Inventory (LEI) developed by Anderson \& Walberg (Anderson, 1973). The LEI was developed as an instrument used with high school and college students to determine their perceptions of the climate of the classroom. Fisher \& Fraser (1981) then modified the LEI to be used with elementary and primary children and re-named it the My Class Inventory. Another revision narrowed the number of items from 45 to 38 . The Fuqua revision used in this study consists of 25 items divided into five subscales. The subscales are (a) satisfaction, (b) friction, (c) competition, (d) cohesion, and (e) difficulty. Examples of questions asked were: "Most of the pupils in my class know how to do their work" and "The class is fun". The alpha coefficients ranged from .58 to .81 when used with third graders (Fraser \& Deer, 1983). The 25-item version of the MCI as adapted by Fuqua (1986) was read to each child and the answers were recorded by the observer on answer sheets. Each session was also audio taped. The higher the score is on a subscale the stronger the children felt that this component described their classroom.

The Organizational Climate Description Questionnaire-

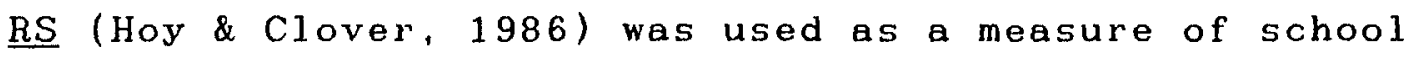


climate (see Appendix D). It is a 42-item instrument with six subscales that describe the behavior of elementary teachers and principals. The subscales are: (a) supportive leader behavior, (b) directive leader behavior, (c) restrictive leader behavior, (d) collegial teacher behavior, (e) intimate teacher behavior, and (f) disengaged teacher behavior. Principals and teachers in each school were asked to rate each statement on a 4-point likert scale as to the extent each characterized their school. The alpha coefficients as reported by Hoy and Clover (1986) ranged from .75 to .95. Sample items from the measure include the following: "The principal goes out of his/her way to help teachers," and "Teachers help and support each other." The Interpersonal Action Survey for Elementary (IASEL) developed by Bifano (1987) was used to obtain a measure of principal leadership (see Appendix E). It is a 20-item instrument with 4 responses for each statement concerning how a principal articulates leadership practice as he or she interacts with teachers in decision making and problem solving situations. An example of the situations and responses included in the instrument are:

"You would like to celebrate the dedication of your school. You are expecting approximately 300 to 400 guests to attend as well as faculty and student body. Items such as: invitations, the program, reception arrangements, decorations, and student involvement need 
to be undertaken. I would:

A-call a staff meeting and appoint committees to undertake activities.

B-at a faculty meeting explain to teachers the need for their help and ask for their input as to ideas on the activities and organization of the dedication. C-at the faculty meeting ask for volunteers, divide activities, and assign to individuals.

D-have the faculty elect teachers to work with P.T.A. and me to plan and undertake activities."

Bifano (1987) reports that the instrument has a reliability coefficient of .78 . The IAS-EL assesses the degree to which a principal exhibits collaborative leadership behavior. The higher one scores, the stronger the behavior. The instrument was distributed to principals and teachers at both schools included in this study.

\section{Population}

The accessible population for the field study were twelve classrooms identified for further study by the Developmentally Appropriate Practices research team. All classrooms were located in one school district in a southern state that is comprised of urban, suburban, and rural schools. The school system served 58,000 students. There are 101 schools in the district, 63 elementary schools, 18 middle schools, 17 high schools and 3 special education 
centers. Blacks make up $54 \%$ of the school population and the other $46 \%$ is comprised of nonBlacks. This category includes all Whites, Asians, Hispanics, and Native Americans.

According to the Hollingshead's Four Factor Index (1975), the population served by these schools ranged from low to upper socioeconomic backgrounds. The SES scores included the full range from $8-66$. The mean score for the Hollingshead was 34.7 and the standard deviation was 14.2 . Another socioeconomic status indicator is the frequency with which children in the district receive free lunch or reduced cost school lunch subsidized by federal funding.

Of the 58,000 students served by the school district, 38,000 are bussed. The school system also busses 4,000 parochial students. The school system is presently under court order to desegregate. All kindergarten students have the option of attending neighborhood schools or being bussed to the cluster schools assigned for first grade.

At the time this study was conducted, the school system was in its first year of implementing a new "pilot schools" program to achieve increased racial desegregation. Seven elementary schools were involved in the first year of the pilot schools program. Each school staff had picked its own enhancement program which was designed to draw in the needed students. Of the seven elementary pilot schools only one was included in the larger study as well as in the study 
discussed in this paper. Its focus was on writing, word processing, and publishing.

\section{$\underline{\text { Sample }}$}

The sample for this study was drawn from the kindergarten children enrolled in two developmentally appropriate classrooms in a local school system. One classroom was located in a suburban subdivision while the other was located in a small town. The sample consisted of 36 children, of whom 26 were white and 10 were black. There were 17 males and 19 females. Both classrooms are apart of a school system that encompasses the entire county.

There were 24 children enrolled in the kindergarten class at Laurel Meadow; 14 participated in the study $(9$ male and 5 females). The 14 participants at Laurel Meadow consisted of nine whites and five blacks. The children ranged from low to middle socioeconomic background with the majority of the Hollingshead scores clustering in the mid 30 's. The mean score on the Hollingshead was 27.3 and the standard deviation was 10.7 .

A total of 23 children were enrolled in the kindergarten class at Woodmere and 22 participated in the study. Of the children participating in the study, 17 were white and 5 were black. There were 14 females and 8 males participating. The children ranged from low to upper middle socioeconomic background with the majority being in upper 
middle socioeconomic range according to the Hollingshead Four Factor Index scores. The mean score was 35.6 and the standard deviation was 13.3 .

To insure the anonymity of the children, teachers, principals, school staff, and schools the names used throughout this dissertation are fictitious and in no way resemble the actual people or school names. Any resemblance to real persons or settings is purely coincidental. Selection of the sample is described in more detail in phase II of Chapter III.

\section{Phase I}

Phase I of the project consisted of obtaining permission from the Associate Superintendent of Instruction for the overall research project. The senior researchers met with the Associate Superintendent for Instruction and explained the purpose of the project and gave him copies of the instruments to be examined. Next, the researchers met with the Director of Research \& Programming and the Supervisor of Research \& Programing to work out the details for implementing the study.

Once the details had been worked out, the Supervisor of Research \& Programming sent a letter to all elementary principals asking for their cooperation with the project but explaining that participation was not mandatory (see Appendix Fl. 
Sixty of the available sixty-three principals agreed for their schools to participate.

The Teacher Questionnaires were then hand delivered to each school to be distributed by the principal to each of the 219 available kindergarten teachers. After discussing the study each principal was given a self-addressed stamped envelope in which to return the questionnaires.

A follow-up was conducted by phone and if necessary, a member of the team went to the schools and either delivered new questionnaires, answered questions, or picked up questionnaires if the envelope had been lost. Of the 219 potential respondents, 204 returned questionnaires. This was a response rate of $93 \%$.

A principle components method of analysis was conducted. The teachers were then ranked relative to their standard scores on the most reliable factor "Developmentally Inappropriate Beliefs" from the extremes of appropriateness to inappropriateness. Those teachers whose scores fell at least one standard deviation above or below the mean were then designated for further study.

\section{Phase II}

In Phase II, 20 of the classrooms that fell at the extremes of the Teacher Questionnaire were visited and rated using the Checklist for Developmentally Appropriate Practice in Kindergarten Classrooms. This instrument was used to 
determine if the teacher's espoused theory was actually in practice. To verify that the selected classrooms represented more and less developmentally appropriate settings, independent ratings were made by two to three members of the research team who were blind to the results of the Teacher Questionnaire. After all observations were completed, observers compared ratings and arrived at a consensus in order to confirm the results of the Teacher Questionnaire.

Two members of the research team visited each classroom on different days and rated it using the checklist. If there were questions, a third member was sent to observe using the checklist. A mean for each classroom was derived and eight classrooms were eliminated. Two were eliminated due to team teaching, one because there was a discrepancy between her espoused theory and actual teaching practices, another because she was a first year teacher and it was agreed that she felt too uncomfortable, two had full time aides in the classrooms, and two were relatively appropriate but less so than the other six selected. Of the 20 available classrooms, 12 were chosen for further study. Six of the 12 were identified as using more developmentally appropriate than inappropriate practices and six as using more developmentally inappropriate than appropriate practices. The six classrooms designated as more appropriate by the research team had mean checklist scores that ranged from 3.91 - 4.60. The six less appropriate classrooms had mean 
checklist scores that ranged from $1.15-2.75$.

\section{Phase III}

During Phase III the actual field work for this dissertation began. It was in this phase that $I$, as the researcher, attempted to gain access to the two classrooms in which I had chosen to conduct my field work.

The initial plan for this case study phase was to investigate one class at each extreme of appropriateness and inappropriateness. The principals were contacted by phone, and a meeting was set up with each one to explain the project and to gain permission to ask for the teachers' participation in the study.

In the spring of 1989 the first meeting with one of each of the principals of an appropriate classroom and inappropriate classroom was held. During the meeting, the significance of the study to the field of education was explained and a letter that explained what the field study would entail was given to each principal (see Appendix G). It was not specifically explained that I would be looking

for stress behaviors during standardized achievement testing. Also, the principals were not aware of the reason for the selection of the particular classroom.

The principal of Laurel Meadow granted permission for me to meet with the kindergarten teacher. The principal indicated that the decision whether or not to participate 
would be left up to the teacher. During the meeting with the teacher the significance of the study was explained and the teacher was given a letter that outlined what the field study would entail (see Appendix G). After answering her questions, the teacher agreed to participate.

Two separate meetings were set up with the principal of Dearborn Elementary but the principal did not attend either meeting. After the second meeting could not be held, I approached the kindergarten teacher before school and discussed the project with her. The same procedure was used during the meeting as with the other teacher. The teacher agreed contingent upon the principal's approval. A third appointment was then made with the principal.

The same procedure was used with the principal at Dearborn Elementary that had been used with the principal at Laurel Meadow. The principal was hesitant, but agreed when assured that the teacher agreed to participate if the principal agreed. During the meeting it was decided that a letter outlining what the field study would entail would be sent to all parents of the students involved in the project (see Appendix H).

The following week the letters outlining the field study were delivered to Laurel Meadow Elementary and an attempt was made to deliver them to Dearborn Elementary. The teacher at Dearborn said that she did not feel that the letter detailing what the field study would entail would be 
sufficient. She requested new permission slips for those participating in the study. It was explained that the research team already had permission slips from the parents. The teacher said she would feel better if new permission slips were obtained. The teacher was assured that this could be done and an appointment was made to deliver the new permission slips.

Two days later I returned with the new permission slips and handed them out to the children. The teacher then requested permission slips from every child in the class whether or not they were participating in the study. The teacher was told that this would be done and I would return the following week to pick up the permission slips with observations beginning in two weeks. The teacher agreed. The following week I returned to pick up the permission slips and the teacher stated that she would encourage the remaining children to return the slips. The teacher was reminded that I would return the following week to begin the study, and she said that would be fine.

The following week I arrived to begin my observations and the teacher stated she did not want any videotaping done until all permissions slips were returned. I agreed but stated that I would like to set up the camera with no film in it just to get the children used to its presence. She denied my request. I agreed but said I would like to stay and observe so that I might learn the children's names and 
general behavior patterns. Again, she denied me access to the classroom until all permission slips were in. I then left the school.

Upon returning to the University I met with the research team and discussed the problems with gaining access to Dearborn Elementary. Due to the narrowing of access, it was decided to look for another less appropriate classroom to include in the study. After contacting all the teachers of the less appropriate classrooms and being denied access it was decided to look for another appropriate classroom.

The principal at Woodmere Elementary was contacted by phone and an appointment made for the following day. The meeting with the principal, followed by meetings with the two kindergarten teachers involved in the overall study at this school took place on Wednesday prior to testing beginning the following Monday. The procedure was repeated with the principal at Woodmere that had been used at the other schools. The significance of the study and an outline for the field work were discussed (see Appendix G). Both of the appropriate teachers participating in the overall study, were approached on the same day to minimize the time necessary to gain access prior to testing because the test was scheduled to be administered the following week.

Meetings were then held separately with each of the two appropriate kindergarten teachers and the project was 
explained. Each of the teachers was told the significance of the study and that the loss of one teacher in the study necessitated finding another classroom. An outline of what the field work entailed was given to each teacher. It was explained that their own use of video taping in their classroom made them ideal candidates for the study. They asked if they could think about it overnight and I said I would call them the next day for an answer.

The following afternoon after school both teachers were phoned. One teacher declined but the other agreed to participate. We agreed that I would come and observe the next day to begin to get to know the children and to begin to get a feel for their behavior patterns.

\section{Phase IV}

Once the selection of the classrooms was completed, indepth observations began. The objective of this phase was to collect thick descriptive data with regard to the children's stress behavior. The study focused on the interaction of the children with teachers; school staff; and peers before, during, and after standardized achievement testing. This was to allow the depth needed to establish behavior profiles for each child and to be able to tell if stress behaviors increased, decreased, or stayed the same during the testing situation.

Four weeks were spent "shadowing" the children at 
Laurel Meadow and three weeks were spent with the children at Woodmere. The reason for one less week at Woodmere was the loss of a week due to the need to replace the teacher that dropped out. During the time spent with the children, extensive journals were maintained of the children's activities and their interaction with others. Audio and video tapes were made of the children's classroom activities and the testing situation. Surveys were made to ascertain staff statistics such as years in teaching, years at that school, turnover rate, and number of degrees. Student statistics, such as number of children enrolled, turnover rate, absences, number of children bussed, number of gifted and special education students, socioeconomic status, number of retentions, and achievement test scores were also gathered. Principals, teachers, children, administrative assistants, and guidance counselors were interviewed both formally and informally to secure viewpoints, explanations of events, and confirmation of data.

The format for the case studies presents a rich description of the setting of the day to day life of the children and their activities and feelings at that time. It is my intent to take you there so to speak, so that the reader can experience what goes on in kindergarten classrooms. The intent is for the reader to "walk in the shoes of the children." 
Analysis of the Data

Analysis of the Teacher Questionnaire was done using a principle components factor analysis. The teachers were then ranked using their standard scores on the most reliable factor, "Developmentally Inappropriate Beliefs" from the extremes of appropriateness to inappropriateness. The teachers whose scores fell at least one standard deviation above or below the mean were then designated for further study unless they indicated they no longer wished to participate in the overall research project.

Observations conducted using the Checklist for

Developmentally Appropriate Practice in Kindergarten Classrooms were analyzed by determining a mean score for each classroom. The classrooms that fell at the extremes were designated for further study unless there were extenuating circumstances that would influence the behaviors of the children. The extenuating circumstances included such things as team teaching, a beginning teacher, presence of teacher's aides, and a significant difference between reported teacher beliefs and actual instructional practices.

The naturalistic observations were analyzed using Glaser \& Strauss's (1967) Constant Comparative method of analysis. The constant comparative method of analysis consists of coding incidents as they occur into as many categories as possible. As the incidents are coded they are compared to the other incidents in the category and soon 
these incidents start to generate the characteristics of the category. The categories are not established ahead of time but develop as the field work takes place. In other words, the data generates its own categories.

To triangulate the data, audio and video taping were done during the observations. The video tapes were then given to three independent observers to view. The observers included a pediatrician, a school guidance counselor, and a family counselor. They viewed the tapes independently and were asked to discuss the children's behavior. No cues were given as to what type of behavior to look for. The comments of the observers were audio taped. 
CHAPTER IV

LAUREL MEADOW ELEMENTARY

\section{Setting}

Laurel Meadow Elementary is located in the town of Laurel, which is a small town covering six square miles. The estimated population during 1989 was approximately 15,000 . The main employers in the area are a large oil refinery, KMart, and the city itself. The majority of the people work in the neighboring metropolitan area. Laurel is of ten referred to by the school staff as a "bedroom community". The socioeconomic level of the area ranges from lower to upper middle with the majority of the residents in the lower to lower middle range.

The main source of revenue for the town for many years was the oil industry. Due to the crash of the oil industry in the early $1980^{\prime} \mathrm{s}$, many businesses either relocated or closed. The town is now dotted by closed businesses which have not reopened. Even though there are numerous closed businesses, there are efforts by the citizens to spruce up the area. One such project that is evident is the planting of shrubs along portions of the main highway. This project is completely staffed by volunteers and has received public thanks on several radio stations in the nearby metropolitan area. 
In the town of Laurel, there are six elementary schools, one junior high, and two high schools. These include public, private, and parochial schools. Laurel Meadow Elementary is located of $f$ main federal highway in a small subdivision. The socioeconomic range for the school is lower to lower middle. The school houses 699 students of which 398 ( $50 \%$ ) are on federally funded free and reduced lunch. Also, $226(32 \%)$ of the students participate in federally funded remedial or special education programs. Of the total number of students who attend Laurel Meadow, $51 \%$ are black and $49 \%$ are white.

The school was built in 1959 and consisted of four separate buildings that housed the offices, auditorium, cafeteria, kitchen, and 12 classrooms. The school is of brick construction with covered connecting walkways. This portion of the school was built to house 300 students. In 1970 "C Building" was added which consists of nine classrooms also attached by covered walkways to the other buildings. This new addition brought the student capacity to 525. The student population during the 1988-89 school year was 699 . Four portable buildings had been added in the late $1980^{\prime}$ s to help with increased student population. Due to over crowding, six more portable buildings were under construction during the course of this project to help alleviate the problem. The over crowded conditions were felt all over the school. One class used the stage in the 
auditorium to hold classes. This class was forced each day to contend with noise from the cafeteria from the three separate lunch periods. The cafeteria was located at the opposite end of the auditorium connected by folding doors. Even with the doors closed the noise was a distraction for the students. The auxiliary staff such as the speech, music, and Chapter I teachers felt the brunt of the over crowding. They were forced to hold classes in partitioned classrooms, storage rooms, and wherever space could be found.

The administrative area is isolated in a small building connected to the other buildings by covered walkways. It contains the offices of the principal, administrative assistant, secretary, bookkeeper, guidance counselor, and the teachers' lounge and workroom. Over crowding was also a problem in the administrative space. This feeling of lack of space was reinforced by the small office facilities which lacked storage and could best be described as closet-like. The offices were extremely small, jammed with file cabinets, stacks of papers and virtually no space for traffic to flow. Each time one entered, the feeling of too many people and not enough space surfaced.

The teachers' lounge/workroom was located in the middle of the building. It consisted of one large room partitioned by folding doors in the middle. Three - fourths of the room was used as a lounge with the usual couch, chairs, end tables and an eating area used by the teachers before 
school, for breaktime snacks, and at lunch time. A microwave oven was available on one side of the room for goodies brought from home as well as the snacks left each morning by the cafeteria staff. The usual clutter of newspapers, magazines and cosmetic ads were found on the tables. The walls were decorated with a monthly calendar for events, birthdays, and reminders as well as cartoons depicting children's behavior at school. One fourth of the room was partitioned off as a workroom using the coke machine and file cabinets as partitions. This area was equipped with a thermofax, two duplicators, laminator, and paper cutter. Due to the amount of furniture, the number of people using the areas, and the stacks of papers and books these areas also exuded an air of over population. Each time I entered this building I was reminded of the stories I had read about the tenements in New York and their claustrophobic conditions. These areas were not dirty but due to a serious lack of space they were very cluttered.

The buildings at Laurel Meadow are arranged in a rectangular shape around the campus. Buildings " $A$ " and " $B$ " are closest to the office and auditorium, and both have center hallways. These buildings house six classrooms each as well as bathrooms. The classrooms are the usual rectangular room with a closet and chalkboard. Along the hallway outside each classroom are displays of students' work consisting mainly of drawings with stories. These 
displays showed evidence of the school's focus on writing and publishing. On most trips through the halls, the doors to the classrooms remained closed and the windows within each door were covered over by paper.

Building " $\mathrm{C}$ " is at one end of the campus and is the newest construction. This building consists of nine classrooms and bathroom facilities for the students. All the classrooms face outward toward the yard and have curtains at the windows. Building " $C$ ", or the primary building as it's called, was designed specifically for kindergartners. There are folding partitions between each pair of classrooms to allow for team teaching but they are always closed. Each classroom has a sink of child height to allow for easy clean up. At either end of "C Building" is a playground. On the east end is the kindergarten playground which has swings, slides, a merry go round, a jungle gym and a metal two level playhouse with a slide. The "big playground," as the children call it, is located on the west end of "C Building". This playground is used by the children in grades 1 through 5. The only equipment on the playground is a few swings and one slide.

Mrs. Karen Thibodeaux is a young, bubbly teacher beginning her second year teaching kindergarten. She previously taught in a federally funded day care center for a year. The 1988-89 school term is her second year at Laurel Meadow Elementary. She is a relatively new teacher, but 
holds the position of grade chairperson. The four other kindergarten teachers have from one year of experience to eighteen years of experience. With the exception of one teacher, all other kindergarten teachers have been at Laurel Meadow longer than Karen.

All of the kindergarten teachers hold B.S. degrees in education. Karen has a B.S. in child development. The other teachers are certified in kindergarten and elementary education except for the newest kindergarten teacher who is taking classes for certification in kindergarten. She is currently certified at the secondary level. The teachers maintain self contained classes but share bus, playground, and cafeteria duty on a rotating basis. All classes have the services of a music teacher and guidance counselor once a week and a physical education teacher twice a week. However, during the time this study was conducted the guidance counselor was out on sick leave and had not been replaced. None of the auxiliary staff has any formal early childhood education background.

Karen is an enthusiastic teacher who is quick to give a hug or smile to each child in her class. She is often greeted in the mornings with a chorus of "Good Morning" followed by a flurry of hugs and kisses from her students. She is very open and accepting to her students, and this is shown by their need to touch and share their experiences with her. On one such morning Billy ran to show her a 
caterpillar he had caught on the playground before school.

Billy: Look! Mrs. Thibodeaux, I caught it on the yard. Karen: What have you got? (Bends down and puts her arm around Billy)

Billy: It's a caterpillar. Can I keep it?

Karen: Let me see if I can find a jar for him. Then you can put him in the science center for the other children to see. Go get in line and I'll see about a jar. (Billy runs to the rear of the line smiling and showing the other children the caterpiliar.)

There are 24 children in Karen's classroom. Fourteen of the children participated in the study $(9$ males and 5 females). Nine of the participants were white and five were black. The children were from a low to middle socioeconomic backgrounds. More than half of the participants are enrolled in the federally funded free and reduced lunch program.

Karen's classroom is arranged into basically four areas. There is a large rug where she conducts her large group lessons and reads stories to the children. This rug area also doubles as the block center and a place for use of some manipulatives. Another area consists of three rectangular tables and one round one which the children use to do written work. The other two areas consist of a dramatic play area and a manipulatives center. 
Each child in the classroom has an assigned seat where he/she sits to complete paper work. Luke, Susan, Sam, and Carol sit at the table nearest Karen's desk. Luke, who wears hearing aids, is attending kindergarten for the second time. He is quiet but has a quick smile. Karen reported that he had been a behavior problem at the beginning of the year but with the help of a psychologist the problem had been resolved. Susan is an outgoing and talkative child who likes to sing. On many occasions she can be heard humming to herself. Sam is a quiet child but tends to do his work without much prompting. Carol is soft spoken and affectionate and can be seen often giving Karen a hug.

Eric, Diane, Patricia, and Matthew sit at the next table. Eric is blond, outgoing and a friend to everyone. Diane is tall and tends to be the leader in the group. Patricia is quiet but not serious. She likes to draw and writes notes to me during the field work. Matthew can be seen giggling with his friends, and his eyes fairly dance with excitement when he's involved with an activity.

At the next table sits Cindy, Billy, and Michael. Cindy is definitely a little lady. She gets distressed if she gets dirty and doesn't like to engage in messy activities. Billy is the clown of this group. He likes to tell jokes and be the center of attention. While Michael is quieter than Billy, he is also very active. His favorite activity is building with blocks. He makes very intricate designs with 
the help of Billy.

John, David, and Bobby sit at the last table. This group as a whole is more talkative than the other groups. John is very active and always has a reason why he must do something. Bobby is very outspoken and tends to want to have things his own way. He is not an unpleasant child, but he will probably make a wonderful addition to a debate team when he is older. David, on the other hand, tends to follow what John and Bobby do.

\section{Instructional Practices}

Karen begins most mornings with a short group time that includes sharing by the children, routines, and discussion about the day's activities. Then the children move to centers. A self selection system is used for deciding where children will go during center time. The children select the centers they wish to use and how long they wish to stay in that particular center. During center time Karen will call children in small groups or individually to work on a particular reading or math skill. All skills are introduced to the whole group and then worked on individually or in small groups. After center time there is usually a group language arts lesson. Then the children return to their seats to do workbooks or worksheets. Language arts lessons include instructions on beginning and ending sounds, rhyming words, and creative writing. A typical lesson found in 
Karen's class would be children's stories using invented spelling. One such lesson was stories about "Teddy Grahams". The children were asked to write stories about Teddy Grahams (a type of cookie). As a group the children talked about key words and Karen wrote them on a large sheet of paper with a picture beside each to help the children identify the words. Next each child was given a few Teddies with the admonishment not to eat them until they had finished their stories. The children then went to their chairs to begin their stories. As the children worked Karen walked around the class helping children as needed. To reinforce the use of invented spelling in the children's writing Karen pointed out what Susan had done.

Karen: Oh, Listen to Susan's story. She's doing real we11. Susan wrote "I like chocolate Teddy Grahams." Look at the word chocolate. See, she didn't know how to spell it so she spelled it like she thought it should be.

A 15 minute recess follows language arts and then the children have lunch. After lunch, Karen does math, social studies, and science. Her math lesson consists of lessons such as number stories using unfix cubes. She tells a story and the children figure out the answer with their unifix cubes. Karen then tells the story again using unifix cubes 
on the overhead projector so the children can check their own answers. After a few stories she lets individual children move the unifix cubes on the overhead while she tells the stories. The children are eager to have a turn. As each takes a turn Luke has a problem so she asks for a volunteer to help him. Michael quickly volunteers. After helping Luke, Michael returns to his seat. Luke then gets another turn and feels more confident about finishing the activity.

One of the science lessons which Karen did was planting seeds. Two or three weeks prior to the lesson she brought in soil and seeds, and let the children plant seeds in paper cups. Once the seeds were planted the children watered them once or twice a week. When the majority of the seeds had sprouted the children discussed in class what caused the seeds to grow and why some of them did not grow. (The children sat in a semicircle around Karen on the floor and were busy examining their plants.)

Karen: Hmm... Okay, let's take turns telling about our seeds. John, you go first.

John: Well, it's green and it looks kinda like grass. Karen: David.

David: Mine's green to but it's bigger n[and] his. Karen: What do you think caused it to grow bigger than John's. 
David: [Shrugs his shoulders]

Karen: Okay, Cindy tell us about yours.

Cindy: [Almost in tears] Mine didn't do like theirs.

[Karen goes over and put her arm around Cindy]

Karen: It' O.K.[to Cindy] Let's figure out what plants need to grow and then maybe we can help Cindy figure out what to do about her plant. [ to the rest of the class ]

Karen: What do you think a plant might need to grow? Don't forget to raise your hands.

The lesson continued with the children being led through questioning to answer that a plant needs soil. sunlight and water to grow. Then it was decided by the children that Cindy and Patricia [another child whose seed did not sprout] should plant another seed just in case the first ones never came up so they would have one to take home.

Through the lessons shared above Karen shows that she is aware of the children's different abilities and needs and tries to meet those needs and abilities. She tries to give the children time to learn through discovery rather than standing before the class lecturing. She questions the children, making them think and come up with possible solutions instead of her dispensing answers.

Karen's reptoire of instructional practices includes 
both those deemed developmentally appropriate and inappropriate in nature. She believes in hands on experience with the use of concrete objects but, she also uses workbooks and worksheets with the children. Karen is quick to point out that she uses both types of instruction but not by choice. When asked, she explained that the principal required her to use the workbooks and checked periodically to see if she had. [Interview after school in her classroom. ]

Karen: I use workbooks but I don't believe in them. In fact, I think they're a waste of time but, Sharon (the principal) says I have to use them. She even comes in my room to see if the children are doing them. She checks on all of us (kindergarten teachers) to see if we're using them.

Pam: What does she say?

Karen: Oh, she just asks if they're (Children) finished with them (workbooks) if they aren't out on the table. Pam: Have you ever not used them?

Karen: Yes, She (principal) didn't get mad. She was really nice about it and just said remember we have to use them cause it's a parish policy. So, I got them back out and use them but I really hate them cause there's so many other things I could be doing.

Her dislike for the use of workbooks and worksheets is 
exhibited when she has the children complete a reading workbook page on beginning sounds.

Karen: All right, I want you to take this back to your seats and draw a line from the pictures over here (pointing to pictures on the left) to the letter that shows it's beginning sound (pointing to the letters on the right).

Sam: Oh, Mrs. Thibodeaux, do we hav't [have to]?

[Other children groan]

Karen: I know, I know, [holding up her hand] I don't like them either but we have to do them. So let's get busy.

[The children slowly go to their seats to begin]

Karen is also forced to use incongruent evaluation practices. She uses teacher observation but also uses standardized achievement tests and criterion referenced tests (CRT) to evaluate the children. The CRT's are used in making decisions to pass or retain a child. The following are selected skills that the CRT's assess that the school district if which Laurel Meadow is located designates as necessary before a child can be placed in first grade:

\section{Social/Personal Development}

1. Shares and takes turns. 
2. Plays and works well with a group.

3. Handles own belongings.

4. Respects rights of others.

5. Follows directions.

6. Works well independently.

7. Finishes a task.

Motor Development

8. Copies 1 ines and shapes.

9. Writes first name clearly.

Concept Development: Identification, Discrimination and Classification Skills

10. Identifies circle, square, triangle, and rectangle.

11. Names colors.

12. Matches related pictures.

13. Matches patterns.

14. Completes patterns.

Concept Development: Math

15. Counts to ten by ones.

16. Counts concrete and semi-concrete objects.

17. Orders numerals 1-10.

18. Compares differences in dimensions.

\section{Language Development}

19. Names common objects and pictures.

20. Expresses ideas and experiences verbally.

21. Infers meaning from positional words.

22. Identifies rhyming words. 
23. Listens attentively.

24. Reorganizes pictures to show the correct story sequence. (Charlesworth, 1987)

Karen is not as opposed to the CRT's as she is to the standardized achievement tests. When asked about how she feels about giving the California Achievement Test (CAT) she stated:

Pam: How do you feel about giving the CAT test to your children?

Karen: [laughs and shakes her head] It's such a waste of time. We spend so much time on preparing the children and then spend a week giving the test. After that, then I have to go through each one (test booklet) to make sure that all the extra pencil marks are removed. That takes almost a week.

Pam: When you talk about preparing the children what do you mean?

Karen: Well [pause] Like we give them papers to do that they have to color in the little circle to answer the questions and if you know that they (the test) ask a question a certain way then you try to ask your questions the same way so the children will be familiar with it. You don't ask the actual test questions just something like them. Do you know what I mean? 
Pam: In other words, you use the question format not the actual questions.

Karen: That's right.

Pam: Are the test scores used when making a decision to pass or fail a child?

Karen: No, As far as I know they aren't used for anything. It's just a waste of time. I could use that time at the end of the year to do a lot of much more worthwhile things.

\section{Principal's Impact on the Teacher and Students}

Sharon Miller is a small woman in her late $50^{\prime}$ 's who seems to always be in motion. She has been principal at Laurel Meadow for the past three years but has taught at the school since it was built. "I've been here as long as the school has" she states proudly. "The year they built the school, I built my house right over there [points to the far side of the campus] and started teaching here that fall." "I've been here all except two years since I started teaching. Those I spent at Newcomb." [A nearby small town] Sharon is rarely in her office and can be found most of the time roaming the halls and in and out of various classrooms. In addition, she seems to know each and everyone by first name and family circumstances. She says hello to each student and pauses of ten to ask about members of their family. During one interview she stated that she felt it was 
important for a principal to be highly visible and know those people that make up the school. "I'm usually here (school) by 4:30 or 5:00 to do my paperwork so by 7:00 I'm ready to deal with whatever problems the day brings.

Each day is usually started with a conference with Susan Daily, the Administrative Assistant. This meeting consists of going over incidents that happened the day before, their solutions, preparation for future events, and things to be accomplished that day. Once the conference is over Sharon heads to the lounge where she greets the teachers who are present and goes on outside to where the children are disembarking from the buses. She makes the rounds of the cafeteria, where the breakfast program is in progress, then the playground, and then back to the office to check on things. Sharon will make these rounds several times before the bell rings for school to begin. As Sharon states, the time before school is spent "putting out fires". She sees it as her job to organize and have everything ready to go for the teachers.

Throughout the day Sharon can be seen going in and out of various classrooms. She makes frequent visits to each classroom just to check on things as she puts it. When asked what kind of things she checks on she replies:

Sharon: Oh, you know like,[pause] what kind of work the children are doing and if there's been a froblem with a 
student the previous day I check to see how his behavior is that day.

Pam: Do you ever check to see if teachers are using workbooks?

Sharon: Not anymore, I used to but now they all use them if they have them. At first some needed a little reminder that it's our policy (school district policy) to use them, but that's not a problem anymore.

Pam: How important do you think the workbooks are to your curriculum?

Sharon: I believe it's an integral part of our program. It allows the children to practice their skills and besides, it's good practice for the CAT tests at the end of the year.

When asked about faculty input into decisions made, Sharon says she relies on her weekly meetings with her grade level chairmen. "They keep me informed about how everyone feels and from this feedback I make decisions," she states. When Karen was asked about the input the faculty had in decision making she laughed.

Karen: Sharon asks how we feel about something but the decision has already been made. It's not that she doesn't care it's just that she has so many plans for the school that she just doesn't slow down long enough 
to hear us and sometimes implements changes too fast. It's funny. She's what I like most about the school and what I like least about the school. Pam: Can you explain a little more? Karen: Well, it's like, she's so nice. She always has something good to say to you. She comes through the lounge in the morning and tells you how glad she is that you're a part of the school and what a good job you're doing. That kind of thing.

Pam: Do you mean you like her interpersonal skills? Karen: That's right.

Pam: What do you mean by she's also what you like least about the school?

Karen: She's always in a hurry. She tries to implement changes too quickly. I realize that she's just trying so hard to do a good job. After all, she's kinda new to being a principal.

During our initial talks about the field work, Sharon indicated that the standardized achievement tests were not overly important for kindergartners because they were not a very good measure of their progress. However, during an interview after the testing she said that they (standardized achievement tests) were a measure of the child's capabilities and considered important by many. The importance of the test seems to escalate for Sharon. This 
was shown when Karen reported to me that Sharon had questioned her about my presence during the testing the first day.

Karen: [Before school on the second day of testing]

Sharon asked me how it went yesterday and how the children reacted to you during the test. I told her it was fine and you were a big help cause you had worked with another class last week that took it.

Pam: Really.

Karen: Yeah, she said if there was any problem to let her know cause she didn't want it to interfere with the children's performance on the test. I assured her you were a big help and pointed out places that were potential problems for the children.

Pam: Thanks, I appreciate that.

Karen also reported that Sharon had told the faculty on a number of occasions that the test was one way the school would be measured by the public. So much emphasis had been put on the test that Karen felt that the only thing that had not been said was teach the test.

\section{Standardized Achievement Testing}

The guidelines for the school system stated that achievement tests would be administered to all students in 
grades K - 8 the last two weeks of April. The CAT test was administered the last week of April at Laurel Meadow. It was decided by the faculty that the test would be administered only in the mornings that week. Through this procedure it would take five days to complete the test.

Karen divided her class into three groups for testing. The smallest group consisting of five students was sent to the Chapter I teacher to test. When questioned about this, Karen said they were the ones that were expected to be hard to test. I asked who decided this and she replied that Susan, the administrative assistant, had. There seemed to be no logical reason for placing the children in the "hard" group because not all the students were low ability, or behavior problems, or students who had been retained. Karen felt it could possibly be that the Chapter I teacher had just asked specifically for these children.

The children left in the room were divided into two groups and stayed in these groups throughout the testing period. One group would have the test administered while the other group worked quietly in centers.

$$
\text { My role in the testing situation was to be an aide to }
$$

Karen. It was my job to see that the children were on the right page and question as Karen read the questions. I walked around the room and helped children locate their question, turned pages, and repeated a question if they needed it repeated. 
Distinct behaviors of individual children seemed to emerge as the days of testing wore on. Luke, who wore hearing aides and is repeating kindergarten, always wanted someone beside him and to have each question repeated to him. The longer the testing situation lasted the more agitated he became. During the last five minutes of the first day of testing he put his head on the table and began to cry. He told Karen he didn't want to do it any more. Karen spoke soothingly to him and assured him it was okay not to know all the answers. She told the rest of the group that the way the test was made there would be no way they could know all the answers so to just do their best.

Many of the children looked at each other's booklets before marking their answers. Karen seemed to be constantly placing books on the table to create a barrier so answers could noy be copied. This did not deter John however, he just stands up so he can see Michael's paper. Cindy and Patricia also copied of $f$ of the children sitting near them which was surprising because one would expect them to do well on the test because they do very well on their classwork. At the end of the second dey Karen tells me she feels like she is fighting a losing battle with the cheating.

Karen: I absolutely hate this. It's not that they don't know the answers; it's just that stupid test. It's the way it's set up. They knew those ending sounds, but 
because they did two rows of beginning sound and then two rows of the middle sounds they kept marking the beginning sounds.

Pam: I know; when you went over it after the test they could tell you the answer out loud but they couldn't seem to mark them on the paper.

David and Eric seem to have no confidence in marking their booklets. After each question is asked they call me over and ask me if what they marked is right. I keep telling them to just mark what they think it is. They both seem to wear perpetual frowns the entire week.

On the third day of the test Susan seems to reach her limit. Halfway into the testing period she closes her book and refuses to open it. She will not say a word to Karen or myself. Karen kneels beside her and says she knows that she is getting tired but if she could just hang in there another few minutes she will be finished and then she can play in the centers. After a few minutes of pleading Susan opens her booklet but looks as if she is going to cry.

The fourth day of testing begins with Luke refusing to come to school. His mother walks him to class and tells Karen that he has been crying and didn't want to come to school but would not say why. Karen tells his mother not to worry and that she can handle it. She put her arm around Luke and draws him into the classroom. She finds errands for 
him to do like returning a book to the library and taking a message to the office to get his mind off his anxiety. She tells me we will test the other group first and let Luke's group go last. Luke's group plays in centers while the other group takes their test.

As Luke's group is called to take their test he reluctantly goes to his chair. Karen has to call him by name three times before this happens. He takes his test but seems to be marking answers at random.

On the last day of testing all three groups of children are present in the classroom because the Chapter I teacher finished testing her group the previous day. The children, who were tested by the Chapter I teacher, spent their time working in centers while the other two groups finish their tests. The two groups being tested continued with the same type of behaviors exhibited on the previous days except there was a growing sense of excitement as the testing drew to a close. The closer it got to the end of the test the more fidgety the children became. Luke, Susan, and Eric bounce up and down in their seats the last 15 minutes of testing. When Karen announced the end of the test the children cheered.

\section{Reflections}

The children at Laurel Meadow seem to show an increase during testing in behaviors that are indicators of stress. 
Some of the behaviors observed included playing with clothing, chewing on pencils, playing with hair, complaining of feeling sick, and gazing around the room. The children engaged in calling out and copying answers. The insecurity associated with the need to copy answers was intensified by the pressure put on the teachers to raise the children's test scores. During interviews the children talked about how unpleasant the test made them feel. From this we can only conclude that there was anxiety associated with the testing situation. Even though Karen engaged in appropriate activities within the classroom, the frequency of stress related behaviors seemed to increase during testing. 


\section{CHAPTER V}

WOODMERE ELEMENTARY

\section{Setting}

Woodmere Elementary is located in the city of Langston. Langston is a metropolitan area located in the Southeastern United States with an estimated population of 447,599 . The city is the site of city, county, and state governments. The largest employer in the city is the state government.

The city boasts an international flavor due to it's being the seat of state government and also having two major universities and a small college within its boundaries. Many of the children whose parents are studying and/or working at the universities attend the schools that make up the school system in which Woodmere is located. It is not uncommon to hear several languages spoken at any given school in the county.

The school system in which Woodmere is located consists of urban, suburban, and rural schools. There are 63 elementary schools, $18 \mathrm{middle}$ schools, $17 \mathrm{high}$ schools, and three special education centers for a total of 101 schools which make up the district. The majority of the children in the school system are black $(54 \%)$, and at this time the school system is facing a court desegregation order. In order to desegregate, the schools have been assigned to 
clusters consisting of three schools, and the children are bussed to achieve integration. Kindergartners are assigned to their neighborhood schools unless they wish to be assigned to another school in the cluster. However, when the children enter the first grade they are then assigned to one of the three schools in the cluster to achieve racial integration. According to the courts this has not been a successful plan, so beginning in the 1989-90 school year Woodmere will participate in a new program as a pilot school. The schools participating in the pilot program offer curricula with a particular focus. All of the normal subject areas are taught while an emphasis is put on a particular area. Some of the enhancements used are computers, visual/performing arts, writing, French, and Montessori classes.

As a pilot school, Woodmere has chosen to have a $\mathrm{K}-1$ transition class, implement a whole language program, and focus on the curriculum areas of math and science. The decision as to the type of enhancement program to offer was made by the faculty by assessing which areas within the school needed to be addressed. The $K-1$ transition class is seen as strengthening their early childhood program and the whole language approach to reading was seen as a plus to all grade levels. The areas of math and science were chosen by the faculty because they felt that they were weak in those areas. Woodmere was asked by the school board's central 
office to offer a Montessori class and the faculty felt this would be in line with the goals they had set, so they agreed. In May of 1989 the school had 150 children sign up for the new enhancement programs. This was a larger response than was anticipated so all of the children that applied will not be accepted into the program.

Woodmere is located in the northern section of the city in a suburban area. The housing subdivision where Woodmere is located is made up of houses constructed in the 1970's. The majority of the houses are of brick construction, and the yards are well kept and usually landscaped. There is also a trailer park located on the west side of the school. The trailer park has about 50 mobile homes with spaces available for about 100. Many of the children that live in the trailer park attend school at Woodmere. No businesses are located within the subdivision. However, several small businesses are located on the state highway which runs just outside the subdivision. These businesses include a beauty salon, auto repair shop, print shop, taxidermy, and a ceramics supply shop.

The school itself was built in 1974. The building is of red brick construction with brick red colored doors and trim. Woodmere consists of a main building with 24 classroom and a small adjacent building that houses three classrooms. Each of the classrooms in the main building has a door that opens into the interior hallways and one to the outside 
yard. The doors to the hallways are open most of the time and the voices of children can be heard as one walks down the hallway. The office, library, auditorium, and cafeteria are all located in the center of the main building and are flanked on either side by classrooms. The hallways are bright and cheerfully decorated with children's art work and stories. The building is well maintained, clean, and orderly.

The administrative section in the center of the building consists of the offices of the principal, secretary, nurse, and guidance counselor. This section also includes the teachers' lounge and workroom. The rooms are spacious and neat. The sense of order extends throughout the school. As with every lounge, it contains the usual couch and chairs as well as a table and chairs for meals and snacks. There is also a drink machine and microwave oven available for the staff's use. The lounge has the usual cosmetics advertisements but several professional journals are also evident on the end tables. On the bulletin board across from the mailboxes, all schedules for playground and bus duty are posted as well as schedules of all auxiliary personnel and announcements that range from thank you notes to notices of policy changes from the school board. A small chalkboard next to the bulletin board is used to write changes in the week's schedule or to notify teachers of special events. On several occasions notes about classes 
being offered at a particular university were posted by individual teachers. The teachers' workroom is located between the lounge and the offices of the secretary and principal. The workroom is a small room with a desk and chair, thermofax machine, duplicating machine, paper cutter and a xerox machine. A phone is maintained in both the lounge and the workroom for the teachers' use.

In addition to the buildings, there are two playgrounds located to the east and south sides of the school. The smaller playground located on the eastern side is the kindergarten playground. It is fenced and features swings, balance beams, climbing platforms made of wood, metal jungle gyms, and a concrete courtyard with wooden benches and seesaws. All of the kindergarten classrooms open onto this playground.

The larger playground is located on the south side of the school and is used by the rest of the children in the school. This playground has swings, basketball goals, and slides. It is also equipped with some wooden benches for seating .

Visitors who enter the school are greeted by several bulletin boards that line each side of the foyer. These bulletin boards are decorated with children's art work and stories. Also, next to the entrance to the office are two small display cases that house trophies won by various teams from the school and prizes that will be awarded at the end 
of a fund raiser that was in progress at the school. The school houses 46.7 students and has a faculty of 26 with 18 of those being regular education teachers. The others are either special education or auxiliary personnel.

The racial make up of the school is $35 \%$ black and $65 \%$ nonblack. All white, Asian, Hispanic, and Native Americans are lumped into this nonblack category. The children are from a low to upper middle socioeconomic background. This is reinforced by the fact that of the 467 children in the school only $179(38 \%)$ participated in the federally funded free and reduced lunch program. Another fact that reinforced the socioeconomic status was that there were no Chapter I services available for the children during the course of my fieldwork because the income level had been reassessed at the beginning of the school year and there were not enough children attending the school who met the low socioeconomic level which would have qualified them for the services. The school had met the criteria the year before but was unable to this school year. The children that would have qualified received only the extra attention their individual teachers could give them. From conversations overheard in the lounge and through interviews with the principal and teachers this was considered a problem.

There were a number of auxiliary personnel available in the school. The kindergarten children received the services of a guidance counselor, librarian, music teacher, and 
French teacher once a week and the services of a P.E. teacher twice a week. The children in the other grades have the services of the above mentioned faculty and also have the option of vocal lessons and string instrument lessons. Several of the teachers are involved with projects connected with the local universities. These include student teachers, students doing observations, and students doing tutoring.

The faculty has an average of 15 years of teaching experience. Of the 26 members of the faculty only four have less than three years of experience. The majority of the faculty have between 15 and 20 years of teaching experience. Four have a master plus 30 graduate hours while $2 / 3$ of the faculty have master's degrees. Most of the teachers live in the area. The teacher turnover at Woodmere has been due to retirement from the profession rather than transferring to another school.

There are four kindergarten teachers at Woodmere, and three of them hold a B.A. degree while the fourth holds a B.S. degree in education. All are certified to teach kindergarten. Their rooms are all located at the east end of the main building close to the office. The classrooms are large with windows facing the playground. Each classroom is equipped with a closet, chalkboard, and sink. However, each class is very individually decorated. Each class has a mascot and that theme is used to decorate the classroom. All the mascots were taken from children's literature. One class 
is Winnie the Pooh, another is Snoopy, a third is Big Bird, and the last is Mickey Mouse. These themes are used throughout the year and the children in the class are referred to by the mascot name instead of the teacher's name. An example of this occurred during the estimation fair. Each class in the school set up a booth and all the children were allowed to go from booth to booth and estimate the weight, length, width, or amount of objects in each booth. The children attended the fair by classes. The following conversation occurred at the fair which took place in the auditorium.

Marsha Eastland (principal): Have the Snoopys and the Poohs come yet?

Susan Faust (secretary): I don't think so. Should I call them?

Marsha Eastland: Yes, there wasn't a designated time. Just tell'em we're ready. (pause) Tell'em don't forget their paper.

Laura Chambers is a black veteran teacher of twenty years. She is small and animated with a contagious sense of excitement. On more than one occasion I heard teachers' remark about her ability to make the most boring subject matter new and exciting. Laura tackles everything with energy. She is never still, constantly moving from child to 
child questioning about the activities they are engaged in. Even sitting reading a story Laura is very dramatic and the children sit with rapt attention. She dresses in costumes on many occasions to as she puts it "To get them [students] in the mood". She also has costumes for the children to wear at certain times that go with the different units that she teaches.

There are 23 children in Laura's class. The class consists of five (22\%) black and 18 (78\%) white children. Of the $23,14(61 \%)$ are female and nine (39\%) are male. The children range from low to upper middle socioeconomic backgrounds. This is reinforced by the fact that only seven (30\%) of the children in the class participate in the federally funded free and reduced lunch program. All the children except for three ride the bus to school. Twentytwo of the 23 children are participating in the study. Laura's classroom is an inviting place for her students. The children in the class are known as Mickey's Munchkins. They all have T-Shirts with pictures on Mickey Mouse on the front and Mickey's Munchkins on the back and wear them frequently to school. The room is decorated using a Disney motif. There are pictures of Disney characters on the walls, on the curtains at the windows, and on the curtains that partition the reading castle from the room. There are stuffed Disney characters in the reading castle and in the home center. The stuffed animals are mainly 
Mickey Mouse with a few of Minnie Mouse and Donald Duck thrown in. Although the Disney motif is worked into all the bulletin boards, the boards also exhibit the children's art work, stories, or photographs of the children.

The children are heterogeneously grouped within the classroom. This grouping consists of four groups each using a Disney name. According to Laura the children are grouped in terms of who works well together. The groups are rearranged if two children have problems getting along. The groups are not rearranged on the basis of an individual incident. Laura indicated that she liked to give the children time to work out their own social situations but if there are two that do not work well together consistently. she usually steps in and makes changes in the groups.

Each group has five to six children and uses a Disney character to identify their group. The groups are named the Mickeys, Minnies, Donalds, and Plutos. The groups use the character as well as a color to identify their supplies.

The Minnies group consists of Sara, Heather, Beth, Melinda, Brian, and Seth. Sara is quiet and smiles of ten while Heather who sits next to her is quite a chatterbox. Seth is extremely quiet and seems sleepy much of the time. Beth is quite talkative, clowns around, and competes with Heather as the leader in the group. Melinda is the mother hen of the group and tries to help Brian who does not work as quickly as the other children. Brian has been having some 
trouble and will probably go into the $\mathrm{K}-1$ transition class in the fall.

The Mickeys group is made up of Rosalind, Fred, Rob, Tiffany, Don, and Jennifer. This group is closer to Laura's desk and the area of the room from which she talks to the whole group. When asked the reason for this group being here she replied, "They're a little more active, so I like to be closer to them cause they need a little more attention sometimes." Rosalind is a happy child with an infectious laugh, who has a Hispanic look about her. Fred is talkative and vies with Don for leadership. This is Fred's second year in kindergarten. Rob is the peacemaker and tries to smooth out the trouble in the group. Tiffany joined the class late in the fall and still has trouble fitting in sometimes. She's quiet around adults but can be heard giggling with her friends when she thinks she's not be observed. Don tends to be loud and has a hard time sitting still. He and Fred try to be the leaders of the group but the girls tend to lead as much as the boys do. Jennifer is also in this group and is best friends with Rosalind and at times excludes Tiffany. The group as a whole is very talkative and active.

The Plutos are a very social group and tend to have an opinion about everything. This group includes Trisha, Susan, Joan, Ross, Ellen, and Mark. Trisha and Mark seem to be the leaders in the group. They tend to be outspoken and vie for leadership in the group. Susan tends to be an onlooker 
wanting to please. Laura says Susan will probably be retained in kindergarten because she has not mastered the required kindergarten skills. Joan and Ellen are quieter than the others, but still have their own opinions. They just seem to state them in a quieter tone. Ellen is also a perfectionist. She gets very upset is if she doesn't do well on all her classwork. Mark never gets in a hurry to do any thing. He is usually quiet and seems to "march to his own drummer".

The last group is the Donalds. The group includes Danie1, Lisa, Tammy, Lee, and Faye. Daniel is smallest of the group and constantly in motion. Lisa is tall and extremely quiet, and as Laura pointed out, is constantly afraid she is going to make a mistake. "She's finally loosened up and is starting to enjoy kindergarten. I'm only sorry that school will be out in a few months before she really gets to enjoy herself." Tammy is outgoing and tends to be a leader in her group. However, she is not ready for first grade as Laura points out. "She's mastered all the uindergarten skills but when you look at what is required for first grade she won't make it. I'm recommending she go into the $\mathrm{K}-1$ transition class. Lee who is repeating kindergarten this year is red haired with freckles and tends to be jovial. Faye is short and tends to be rather serious. She seems to brighten when she is actively involved with manipulatives. 


\section{Instructional Practices}

Laura uses a theme approach to instruction in her classroom. She is extremely active in the area of science. In fact, she has co-authored a science activities book that is marketed locally and does many presentations for area teachers. Many of her units come from the science and social studies areas. Among the topics covered during the year were dinosaurs, bones, community helpers, and farms. A new theme is introduced every two to three weeks. All activities are geared to the particular theme being used.

During the dinosaur unit she brought out plastic dinosaurs and they discussed their names, where they were found, and how they lived. Music and movement time used dinosaur songs. Paintings and drawings of dinosaurs were done in the area of art. In the math area number stories about dinosaurs using popsicle sticks were done. Stories like Danny the Dinosaur were read to the children. Sorting the dinosaurs by the beginning sound of their name was an activity done for language arts.

In addition to the activities done by the children, there were many materials available to them in the classroom that reinforced the dinosaur theme. Some of the materials available were dinosaur puzzles, stuffed animals, books, dinosaur bones, and miniature plastic dinosaurs. In the center of the room was a large sheet of plastic that was decorated to look like water and land. The children used the 
plastic dinosaurs to play out scenes about how the dinosaurs behaved. Each day one child was allowed to take a special dinosaur cup and a stuffed dinosaur to lunch with him/her. This was continued until all the children had a turn. On the last day of the unit Laura would dress up in her dinosaur costume and bri.lg one for the leader to wear that day.

The end of the unit on dinosaurs coincided this year with the estimation fair. The children decided to use in their booth the largest blow up dinosaur and have the students estimate how many paper clips long the dinosaur was. Prior to going to the fair each child made a guess and it was put in a bowl. The children who guessed correctly were announced that afternoon.

In conjunction with Laura's interest in science, many interesting things can be found in her room. One area of the room is set up in what she calls a discovery center. In this center can be found a small turtle pond with turtles, a live spider caught on the playground at the beginning of the year, bird nests, bones, feathers, a terrarium, snake skins, snakes in formaldehyde, butterflies, an incubator with eggs, and plants. In other areas of the room are fish, gerbils, finches, and a cockateel. As Laura states, "People are always bringing me things. They know I keep everything." The reading castle set up near the back door serves double duty. On the inside it has pillows, books, stuffed animals, and puppets. Once the curtains are closed it turns 
into a puppet stage and tise children frequently put on impromptu puppet shows during center time. This area also serves as a quiet place where the children can get away from the noise and bustle of the classroom if they have a need for a little privacy.

Another area of the classroom is devoted to art and dramatic play. This area is most often called the home center. In this center can be found loads of old clothes, shoes, hats, cooking utensils, and various other materials. During the time of my fieldwork, a fireman's hat and boots and a doctor's stethoscope and headband with light could be found in this area left from a previous community helpers unit. These materials were in addition to the many costumes that are normally found in the center. An easel, paint, and different types of paper can also be found in this center. During center time Laura assigns a group of children to a particular center but they are free to choose from the many activities in each center. Prior to the beginning of center time she tells the children the order in which the: will go from center to center. For the most part, each child has a chance to spend time in each center every day. Before it is time to change centers Laura will give the children a five minute warning so thes can wind up their activity before going on to a new center. Five minutes after the warning she will announce clean up time and the children clean up before moving to the next center. For most 
transitions Laura either sings a particular song or plays records having to do with the particular theme as the children's signal to move to the next center.

The morning hours are more structured than the

afternoons. During the mornings the children participate in whole group and small group activities in the areas of language, social studies, math, and science. The afternoons include centers, rest time, snack, and culminating activities. Through out the day the children are encouraged to interact with each other. This is shown by their willingness to talk quietly while Laura is taking roll and doing the morning business. Also, the children chat during the periods they are seated at their tables working. An example of this is:

[Children are seated at their tables drawing pictures of dinosaurs]

Brian: Mark came over to my house yesterday. We ate Bar-B-Q.

I know how to cook it, too.

Sara: uh, huh.

Beth: You know my dog, he licks me all over. [giggles] [Other children giggle]

Heather: My mama cat had babies.

Brian: When?

Heather: This weekend.

Beth: How many? 
Heather: Four. My mama says we're gonna have to get rid of them.

Sara \& Brian: Can I have one? [said at the same time] Heather: I'11 ask.

These types of conversations are very common among most of the children. Lisa, however, rarely joins in these conversations. She tends to be very serious. When I inquire about this, Laura says Lisa talks very little but is beginning to open up. She also states she worries about her because she seems to put an increasing amount of pressure on herself. "I know it's not her parents doing it because we've talked about it several times and her mother is real easy going," says Laura.

During whole group activities Faye, Lisa, and Daniel tend to check the answers of the children around them before trying to answer whatever question Laura has asked them. Ellen on the other hand tends to answer the question then check around to satisfy herself that her answer is the same as all the rest. This behavior is understandable because when questioned Laura reported that Faye, Lisa, and Daniel are among the lowest functioning in the class. Faye tends to wear a frown whenever she get to an activity that she is unsure of. Ellen, on the other hand tends to be a perfectionist and doesn't like to make mistakes. On one occasion Ellen was almost in tears when she couldn't figure out how to make letters for the ending sounds that Laura was 
calling out. The children had been given popsicle sticks and circles. Laura called out two before she noticed Ellen having trouble.

Laura: What's wrong Ellen?

Ellen: [Shrugs her shoulders]

[Laura goes over and squats down next to her]

Laura: Is it that you don't know what dog ends with?

Ellen: [Shakes her head] "g"

Laura: What are you having trouble doing?

Ellen: [Tearfully] I don't know what to do with these?

[Holds up sticks and circles]

Laura: Remember how a "G" looks? [She moves the sticks and circles to make the letter] and a "B"? What about an " $M$ " [Ellen begins to move the sticks and circles] That's right I knew you would remember.

Ellen smiles and the lesson continues.

The children are also encouraged to help each other and work as a team. This can be seen whether the children are working individually or in groups. During art the children were working on pictures on where dinosaurs lived.

Don: Look at Tiffany's; she made a plant in a pot. They didn't have those.

Jennifer: Well, she can just color it fatter and say it's a tree.

Rosalind: Or try to erase it. [Jennifer and Rosalind nod and smile at Tiffany] 
On another occasion the children were working in centers and Rosalind was having a problem putting a three foot dinosaur puzzle together. Rob noticed that she was becoming frustrated and offered his help.

Rob: You need me ta [to] help ya [you]?

Rosalind: [nods her head]

Don: Com'on Rob. Let's finish.

Rob: Naw, I gotta help Rosalind first. [pause] Just wait a minute.

Don: [sighs heavily, but waits]

Once Rob helped Rosalind find a few pieces he moved back to Don and they continued working with unifix cubes and number 1 ines.

Assessment to Laura consists of teacher observation and a few pencil and paper activities. Her methods of assessment are interwoven within the daily activities of the classroom and so the skills are not taken out of context to evaluate. Laura rarely pulls students out individually and assesses them. If for example she is assessing the child's ability to write his/her name she will ask the children during the course of an activity to remember to write your name on your paper. Laura does this instead of calling the children one at a time and asking them to write their name. Another example would be assessing the area of beginning sounds. Over a period of weeks the children would have engaged in activities such as sorting objects by beginning sound as a 
large group with Laura's help, in small groups sorting objects, and individually sorting objects during center time. Then she would assign this type of activity to a small group and observe as they took turns placing the objects on cards showing the beginning sound rather than giving them a worksheet and asking them to circle the correct letter as she called out words.

She does use the school system's criterion reference tests (CRT) to make decisions about passing or retaining a child but the tests are not her only basis for her decision.

[One afternoon after school in Laura's classroom] Pam: On what do you base your decision to pass or fail a child?

Laura: Wel1, I look at their CRT scores but that's not all I look at. I also look at the child to see how well they will fit in with the first grade curriculum and what's expected of them. You know that because of the difference between what they are expected to know in kindergarten to pass and what they are expected to be able to do in first grade some kids fail. You know some kids master what's expected in kindergarten but still aren't ready for first grade. I guess that's because what used to be expected of older kids is now expected of kindergarten and first grade children. What I mean is [pause] I try to look at the whole child and what 
would be best for them as an individual.

Pam: Do standardized achievement tests play a role in your decisions?

Laura: [ laughs] Heavens, no. They're useless. They don't go with the way we teach and really don't show what a child can do.

Laura does administer a standardized achievement test at the end of each school year but does not like to be involved with it. In our initial interview prior to the beginning of the fieldwork Laura explained her feelings about administering the California Achievement Test (CAT).

Laura: I give it but I think it's a waste of time. I wish they (members of the school board) could see what it does to the children. They just get so, so, [pause] stressed out. Know what I mean?

Pam: What are the scores used for?

Laura: Nothing. We just give it cause we have to and all it does is get the children all hyped up for no reason. It doesn't really show what the children can do. According to research they're not valid for young children and I believe that. But since we have to give it we try to make it as easy for the children as possible. We don't put much emphasis on it and try to make it as stress free as possible. Most of all we try not to use the word test. The word test seems to send some kids into orbit so we're as low key as possible. 
Laura shows some concerns about the standardized achievement testing situation and appears to keep up with current research. She however, feels pressured to engage in a practice that she feels is in opposition to her personal philosophy.

Principal's Impact on the Teacher and Students

In addition to the teacher, the principal can also have an effect on the children. Marsha Eastland is a tall, softspoken person who quickly puts you at ease. This is her second year as principal. She has a B.S. degree in history and a masters degree in education and one in computer science. Marsha also has a degree in early childhood education and is certified in administration and supervision. As she states, "I have enough odd hours for a Ph.D. but you know you fool around and fool around and don't direct it. I regret that I didn't direct it." "You know, I did my resume one time and I've been in school since I was two all except for about five years". Previously, Marsha was an administrative assistant for two years and a teacher before that. Marsha is almost always smiling and tends to have an open door policy as far as her staff is concerned. During our many conversations and interviews I found her quite knowledgeable in the area of early childhood education. She not only quoted research but tried very hard to implement it into her school. As she told me in our 
initial interview, "Children have to be active to learn and we've got some good teachers here who know a lot about young children. I really rely on their judgement."

Very few children are seen in the office as discipline problems. Marsha believes children should be responsible for their own behavior and works with her teachers on redirecting the child's behavior when possible and discussing the possible results of misbehavior. She states, "They (the children) have to be responsible for the consequences of their actions." "I don't want to see the child up here unless the teacher has tried everything she can think of." "Usually, the teacher and I get together and try to figure out some type of intervention before the child winds up in the office." "It's better if it [behavior problems] can be handled in the classroom cause if the child is sent to the office it gives him the impression the teacher can't handle it and that's not good."

When asked about corporal punishment she acknowledged that the school system allowed it but that she didn't believe in it. "It doesn't really do any good. It sends the wrong kind of message. If a child has been fighting and you spank him all it says is whoever is bigger wins and that's not what I want these children to learn." "We do a lot of counseling and for the most part have been successful at it. Some children take longer than the others but it's worth it". says Marsha. 
During one interview in her office I asked her what she felt was the most important role as a principal?

Marsha: That's hard cause as a principal you have a dual role. Your an administrator and a supervisor of instruction. People want to see you as a supervisor of instruction and that's critical but that's not always the way the time is spent. I think administrators constantly spend their time weighing that balance. The best solution would be to have two people who could trade jobs each year. One year one would be involved in instruction and the other would do administration and the next year they would trade. But in reality $I$ spend probably about $80 \%$ of my time in administration and that leaves only $20 \%$ for instruction. I'd rather spend it in instruction cause that's where my training lies but if a building is not well administered instruction can't go on so I try to balance them as well as I can. Pam: So, you say it's kind of different from day to day. One day it's more administration and on another day it could be more instruction.

Marsha: Yes, that's right.

Marsha is not a principal who walks the halls constantly. She's usually at the door as the buses pull up in the morning and can be seen frequently saying hello to one child or another. Many of the kindergarten and first grade children give her a hug as they go by. Marsha usually 
makes her rounds during lunch and recess. In the cafeteria she picks a different class each time to eat with. When asked about her visits to the cafeteria she stated:

Marsha: I think it's important that the children see a principal and realize we're people just like anyone else. Besides I've done some of my best counseling over lunch. By eating with a different group each day I get to stay in touch with the students and find out what they think. Of course, I don't get to do it every day but I try as often as possible.

Decision making seems to be a collaborative effort at Woodmere. Marsha seems to rely on her staff and trust their opinions. Committees are formed through volunteering not by appointment. Issues are then studied and opinions of the rest of the faculty are gathered and discussed. Either the committee or its chairman will meet with Marsha and discuss possible solutions. Most decisions are made in this manner. When questioned about the decision making process Marsha responded:

Marsha: I like to get the faculty's input cause they may see something that I don't. I trust their judgement. After all, they're in the positions they're in because of their expertise. They're good and experienced. That counts for a lot. Besides if I force them to do something the likelihood of the policy actually be implemented is slim. 
Laura was also questioned about the decision making process at Woodmere.

Pam: How are decisions made here? I guess what I mean is, how much input do teachers have in the process? Laura: Well, teachers have a lot of input. Committees are formed to make most decisions unless it's something that has to be decided real fast. Marsha makes teachers really feel included in the running of the school. She doesn't say you have to be on any of the committees it's just kind of understood. I don't think anyone really minds. It gives us a chance to have our say. Besides Marsha makes you feel like your opinion is important.

During the course of the field work I interviewed Marsha about the importance of the CAT test and how reflective the scores were of a child's everyday performance.

Pam: How important are the test scores of the kindergarten children in this school? Marsha: What test scores?

Pam: The CAT scores that the children took a few weeks ago.

Marsha: Oh, those. Well, they're an indicator and I look at them but I don't know how much weight I put on them. I look at a lot of things when I look at a child's performance. Scores from tests are all 
indicators but $I$ don't know how valid they are especially with young children. I would rather look at what a teacher has to say about a child or bring the child in and ask if she recognizes these letters or can make these sets. To me I can find out more that way than through pencil and paper tests. I know this sounds hypocritical but I'm not sure if these kind of tests are valid for young children. You know, it's hard to say that we're measuring exactly what we intend to measure.

Pam: How reflective do you think the scores are of the child's everyday performance?

Marsha: Oh, that's a hard one. I never really looked into it. It would depend on the child. If the child were mature enough and had, had enough experience with pencil and paper activities it might be very reflective. However, if the child is developmentally young she probably won't have the fine motor skills that will allow her to perform so it wouldn't show you what she could do. I would rather see an activity oriented test but that's not always manageable. So, [slowly] I guess I would say that any test score would be an indicator but you would have to look at all the other indicators before you can get a true picture of the child.

I was left with the impression that test scores did not 
receive much emphasis in the school. The scores were certainly looked at but were not the last word about a child's performance. Marsha also did not put much emphasis on administering the test. She encouraged the teachers to be low keyed about them. There were no announcements made over the intercom about their importance or reminding the children to get the proper rest and so forth. The county school system administration did require that each child's parents be notified of the testing dates and be given a list of helpful hints to prepare their child for taking the test. The 1 ist included things such as being sure to get adequate rest the night before and eating a good breakfast before going to school.

\section{Standardized Achievement Testing}

The CAT test was administered the third week of April at Woodmere. Laura divided her class into three groups consisting of 7-8 children in each group. As Laura tested one group the other two groups went into the language teacher's room next door and did different kinds of activities. They colored, played with clay, sorted objects, and 1 istened to stories.

The individual group being tested was seated at two tables at the front of the room. My role in the testing situation was strictly that of an observer. The test was administered only in the morning hours during the week. 
Laura began by testing the lowest functioning group each morning. This was followed by the average functioning group and last, the highest functioning group. When questioned about this practice Laura stated:

Pam: Why are you planning to administer the test to the children in this particular order?

Laura: The group I'm starting with will probably have the most trouble with it and will probably take the longest to finish. This way I get them when they're fresh and I don't have to rush them.

Pam: Are you saying the other groups might not take as long to finish the same part of the test as this group? Laura: That's right. This way they can take all the time they need unless it's a timed part.

The first group tested each morning consisted of Lisa, Daniel, Brian, Rosalind, Tammy, and Susan. Laura divides them into two groups and tells them they are going to do some activities today using these books and she holds one up for the children to see. Faye begins to frown as Laura hands out the books. Laura tells the children to be careful not to make any extra marks on the books and shows them how to fold the pages and use the construction paper marker to find their place. As the test begins all the children are quiet but Lisa is tapping her foot and Daniel is biting his lips. As Laura reads the first example, Daniel calls out the answer and she walks over and quietly tells him to mark the 
answer on his paper and not tell her out loud. Susan watches Daniel mark his paper before she marks hers. As the test continues Rosalind and Tammy frequently call out the answers as Laura reads the questions. Several times during the test I see Susan, Rosalind, Tammy, and Lisa watch the other children mark their answers before marking their own. As the testing session wears on Brian slumps further and further in his chair until I begin to wonder if he will end up on the floor. This does not happen because Laura walks over and quietly asks him to sit up straight in his seat. Just before this session is over Lisa begins to roll her pencil over her face and yawn.

Laura tells the children to close their books cause they are finished for today, and Daniel and Tammy cheer. The children are told to get their cups (this holds, pencils, scissors, and crayons) and go to Mrs. West's room while she works with the next group. Laura asks Lisa to tell the second group to come to the room.

The next group consisted of Faye, Lee, Sara, Mark, Fred, Don, Melinda, and Tiffany. As the children took their seats Laura repeated the same instructions that she did with the first group. Before Laura read the first example Faye was already wearing a frown. She wore this frown almost throughout all of the testing. About the only times I saw her smile during that week was during recess and center time. Both of these time periods followed the testing each 
day. Mark sits most of the time slumped in his chair during the test. Melinda twists a strand of her hair as Laura reads the questions. Faye tends to watch Lee before marking her answers. Laura notices Faye watching Lee and tells her to "Trust your brain it will tell you the right answer." Toward the end of this testing session Tiffany is yawning and Mark is sucking his thumb. When they finish Laura asks them to stand up and stretch real big before going back to Mrs. West's classroom.

The third group enters laughing and chatting among themselves. This group includes Rob, Heather, Joan, Jennifer, Beth, Ellen, Trisha, and Ross. After the children are seated and the books are passed out Laura gives the same instructions as she gave the other groups. As the test begins Beth watches Trisha to see how she answers before marking her answer. Ross calls out the answers to the first few questions and Laura reminds him to mark his paper instead of saying it out loud. He stops calling out the answers to her but continues to mutter them to himself. Joan watches Rob to see how he answers and Rob is watching Heather and Jennifer. Jennifer sighs and marks her paper then Rob marks his followed by Joan marking hers. Beth begins saying the answers out loud when they get to the section on rhyming words so Laura asks her to keep her excitement in her pencil. Ross, Beth, and Trisha think this is so funny that they make a game out of seeing who can look 
the most excited as Laura reads the questions. Ellen wears a serious expression on her face and occasionally checks the other children's answers around her to see if they are the same.

The other four days of testing consisted of many of the same behaviors. Lisa, Susan, Daniel, and Ellen spent the majority of their time copying their answers from the other children or checking to see if their answer was the same as those of the children seated at their table. Some of the comments heard during the time the children were taking the test were:

Susan: Oh, my god! [she began to erase an answer furiously]

Lee: This is hard. [to Laura during the section on money ]

Ellen: Oh, this is hard. [ to no one in particular during math section]

Joan: I don't know what it is but I'm gonna mark what I think it is. [to Trisha]

The behaviors that Laura's class exhibited during the testing situation were more passive in nature than some of the more demonstrative types of behaviors reported in the Laurel Meadow case study. The children tended to frown a lot, use their pencils in an inappropriate manner, and copy answers from the children sitting around them.

During interviews with the children after the testing 
was finished the children reported that they did not like to take the test. Ross said that it was boring. Ellen just said it made me feel bad. When asked if their parents had said anything to them about the test, most reported that their parents had asked how they did on their test each day when they got home from school.

Others reported that their parents urged them to go to bed early and eat a good breakfast and that they needed them to do well on their tests.

\section{Reflections}

The children in Laura's class were subdued in their behavior during testing. I did not notice the enthusiasm and smiles during testing that seemed to characterize the children during their daily instructional activities. The children engaged in much language during the administration of the test which is not considered appropriate for the situation but shows that the testing situation doesn't fit the normal instructional mode of the classroom. The children seemed to get more anxious as the days of testing wore on. Many mornings were greeted with groans and choruses of "Do we have to?". On the last day of testing Laura announced that there was just one more page and they would be finished with the test. Several of the children cheered. Beth was so excited that she bounced up and down in her chair throughout the entire last page. Faye, who never seemed to smile during 
the test, was smiling during the administration of the last page.

From the behaviors observed, the children definitely felt relieved when it was over. 
CHAPTER VI

SUMMARY, INTERPRETATION, CONCLUSIONS, AND FUTURE RESEARCH

This chapter begins with a summary of the data from Phase I, II, III, and IV as presented in Chapter Three. The chapter continues with an interpretation of the behavior of the children in two classrooms during standardized achievement testing in the case studies presented in Chapters Four and Five. Conclusions and recommendations for future research concludes the chapter.

Phase I, II, and II I

In Phase I the Teacher Questionnaires were hand delivered to each school to be distributed by the principal to each of the 219 kindergarten teachers in the school system. Of the 219 potential respondents, 204 returned the questionnaires. A principle components analysis was conducted and the teachers were ranked on the most reliable factor, "Developmentally Inappropriate Beliefs". Those teachers whose scores fell at least one standard deviation above or below the mean were then observed and rated using the Checklist for Developmentally Appropriate Practice in Kindergarten Classrooms. Twenty classrooms were rated using this checklist.

During Phase II this checklist was used to determine if 
the teacher's espoused theory was actually being practiced. Of the 20 classrooms rated using the checklist, 12 were chosen for further study. Of the 20 classes, some were eliminated for a variety of reasons. The causes of elimination were: (a) two of the teachers were team teaching, (b) one was a new teacher with no prior experience and who the research team felt that she might be uncomfortable being observed, (c) two had full time aides in their classrooms, (d) one's espoused beliefs were extremely incongruent with her practices, and (e) two were relatively appropriate in their beliefs and practices but less appropriate in their practices than the others selected.

Of the 12 classrooms chosen for further study, six were identified as using more appropriate practices than inappropriate practices and six were identified as using more inappropriate practices than appropriate practices. The mean scores of the more developmentally appropriate classrooms ranged from 3.91 - 4.60. The mean scores of the less developmentally appropriate classrooms ranged from 1.15 -2.75 .

During Phase III two teachers were asked to participate in the testing part of the study discussed in chapters four and five of this dissertation. The two were chosen from the twelve classrooms selected for further study by the research team. Phase IV of the study consisted of the case studies. 


\section{Interpretation}

\section{Laure1 Meadow}

Laurel Meadow was a study in contradictions. The teacher believes in developmentally appropriate practice but does not always use it. She does not believe standardized achievement tests are valid, but she administers them. She engages in these inappropriate tasks under pressure from the principal and because the school system has mandated that the achievement test will be given. The teacher is frustrated because she is having to do things that go against her theoretical beliefs. This frustration may be passed on to the children. When the children engage in less appropriate activities they may exhibit the teacher's frustration about the activity.

The principal is also full of contradictions. She talked about activities that were appropriate for young children and how important they were but required the teachers to do inappropriate activities with the children. She also said the achievement tests were not important but the closer it got to the administration of the test the more nervous she became. During faculty meetings she stressed the importance of the test to the teachers and to the children. She lectured the children over the intercom about the importance of getting enough rest and eating a good breakfast so they would do well on the test. The principal 
also encouraged the teachers to incorporate the test format into their instructional practices so the children would be "test wise."

It is not surprising, with this behavior exhibited by the staff, that the childron would feel pressure to "perform" on the test. Over the week-long testing period, I watched the children become more and more irritable as the week wore on. They engaged in behaviors that were not consistent with their behavior before or after testing. Many of the children frowned frequently, chewed on their pencils, twisted their hair, played with their clothes, and complained of being tired. They copied answers from the children sitting around them. The copying was done by high ability as well as by lower ability children. The children would change their answers to match those around them even when they knew the correct answer. During interviews, the children were asked some of the test questions which they had marked incorrectly and the children answered them correctly. They also called out the answers. The children asked constantly for reassurance that the answers they marked were correct. One child cried during testing and later refused to come to school. He had to be led to the classroom by his mother. Another child closed his book and refused to continue.

The behaviors exhibited by the children were not typical of their behavior before or after testing. The only 
time I observed some of these behaviors before or after testing was when the teacher had the children do worksheets and when overwhelming construction noise could be heard in the classroom. The construction noise occurred only prior to testing. The frowning, playing with clothes, and twisting of hair was exhibited but not with the frequency that it appeared during testing. No crying or refusal to complete the worksheets was observed. The worksheet activity was done for a very short period of time and was then followed by activities that are considered more appropriate, whereupon the behaviors disappeared.

The frequency with which the behaviors occurred during testing could be due to several things. The testing situation at Laurel Meadow was not the best. One group was tested while the other group played in the room. The noise level at times was more than would normally be acceptable for a testing situation. At times the testing had to be stopped to settle a dispute between some of the children not being tested.

The children's ability to mark their answers in the booklet could have had an effect on the frequency of the behaviors' that occurred. The children were asked to mark answers in a booklet by coloring in a small circle. Some of the children did not exhibit the fine motor control necessary to complete the task. After the test was completed, the teacher had to take each book and erase the 
many marks made by the children so only the small circles were colored.

Another problem with the testing situation was that the children were not to answer the questions verbally. Much of the instruction that takes place in that classroom is verbal and even when paper work is done the children are encouraged to talk about it and to help the children around them.

During the testing the teacher repeatedly warned the children not to copy answers and not to say the answers out, loud but they did not comply. When they copied answers, they just looked to see if the teacher was watching them, and if she wasn't, then they copied. When asked not to say the answers out loud, the children would stop for a while but would start again in a few minutes.

The principal's emphasis on the test was felt by the children. She made announcements each afternoon about getting enough rest and eating a good breakfast and each morning wished them good luck on their tests. The children felt that the test was a "big deal" even though they were assured by their teacher that it was not. By putting pressure on the teachers for the scores of the children to increase, the principal put pressure on the children. A feeling of tension permeated the entire campus.

Due to a low response rate, no conclusions could be drawn about the school's climate using the Organizational Climate Description Questionnaire - Revised (OCDQ-RS) or the 
principal's leadership style using the Interpersonal Action Survey for Elementary (IAS-EL). However, the data collected during interviews and from the My Class Inventory (MCI) administered to all children participating in the study indicated that they felt a high degree of satisfaction and cohesiveness in the classroom. The mean scores for the MCI subscales were: Satisfaction 13.0, Friction 8.1 , ":Competitiveness 9.1, Difficulty 9.6, and Cohesiveness 13.0 . The higher the score is on a subscale the stronger the children felt that this subscale described their classroom. These attitudes contrasted with their responses when asked how they felt the testing. They felt the testing was stressful. When asked how the testing made them feel they made statements such as:

I didn't like it.

It was boring.

Some of the stuff I didn't know.

I didn't want to do it.

It made me feel bad.

The comments that the children made indicated that the testing situation was not a pleasant experience. At best, it seemed to be a frustrating situation for both children and teacher.

In addition to the pressure from school, the parents may have been putting pressure on the children to perform without being aware of it. Almost all of the children 
reported that their parents asked how they did on the test each day. Several of the children reported that their parents told them that they wanted them to do "good" on the test. Without meaning to, the parents may have been indicating to the children that this test was very important to their future. One child did report that his mother told him he had to pass the test or he would not go to first grade. This particular child engaged in much copying during the test.

When the children were engaged in appropriate activities the behaviors exhibited which are said to denote stress disappeared. These same behaviors reappeared when the children were engaged in less appropriate activities but not with the frequency with which they were exhibited during testing.

\section{Woodmere}

Woodmere is a low keyed school. Everything is organized and well thought out. The school has an open feeling about it. The doors to the classrooms are open and everyone seems to be smiling. This includes both faculty and students.

The teacher involved in the study also exhibits these qualities. She is organized, well prepared, and low keyed in her behavior toward the children. She does not raise her voice to the children but encourages them to work out their own problems. She is quick to step in if a solution cannot 
be found. Learning is a pleasurable experience in her classroom. While having a calming effect on the children, the teacher is also enthusiastic about what she does and transfers this to the children.

The teacher believes in developmentally appropriate practices and uses them in her classroom. She does, however, administer a standardized achievement test at the end of the school year because it is mandated by the county school system.

Every attempt is made to make the administration of the test as stress free as possible. The word test is not used by anyone at the school. No announcements are made over the intercom about them, and teachers are not urged to teach the format of the test prior to the beginning of the test.

The principal does not rely heavily on tests and puts no pressure on her teachers to raise test scores. They are encouraged to administer the test fairly but to put little emphasis on it for the students. She is aware of the types of appropriate activities that young children should be engaging in and encourages her teachers to use them.

Data collected through interviews and by administering the My Class Inventory (MCI) to all the children participating in the study indicated that they felt a high degree of satisfaction and cohesiveness in the class. The mean scores for the MCI subscales were: Satisfaction 14.0, Friction 7.5, Competitiveness 10.3, Difficulty 9.1, and 
Cohesiveness 14.4. However, due to a low response rate, no conclusions could be drawn about the school's climate using the Organizational Climate Description Questionnaire Revised (OCDQ-RS) or the principal's leadership style using the Interpersonal Action Survey for Elementary (IAS-EL).

Woodmere seemed to have the optimum testing situation. Only the group being tested is present in the room and the entire school is relatively quiet throughout the week of testing. Even though the setting is positive, the children still exhibited behaviors said to be indicators of stress. There was no crying or refusing to do the test but there was much frowning, twisting of hair, pencil tapping, playing with clothes, chewing on pencils, and copying of answers. Many of the children also called out the answers. These types of behaviors were not observed in the classroom when testing was not in progress except in two instances. One little girl frowned almost continuously during testing and some during the course of a regular day but it was more frequent during testing. The other instance was a little girl who is to be retained this year. She tended to copy most of her work from others. However, the frequency of this behavior increased during testing.

There was no pressure put on the children at school to perform on the test but possibly there was pressure from home. Most of the children reported their parents asking them each day how they did on the test. Many of the parents 
also sent the children of to school in the morning with phrases like "Good luck on your test; Do good on your test; and Do your best." Parents may have been putting more pressure on their children than they realize. Interviews with the children indicated that they believed that their parents felt that this test was a "big deal." That was not the impression the school wished to make but that is what the children perceived. When asked how they [children] felt about the test they stated:

Oh, Brother! [child groaned and fell back on the rug] I hated it.

It wasn't any fun.

I didn't like it.

It made me feel bad.

From the comments given, one could tell that the testing situation was not a pleasurable experience. On the last day of testing when the test was completed, several of the children cheered and clapped. Most of all, everyone was smiling again.

\section{Conclusions}

Two different portraits of classrooms during testing have been presented. What is striking is the similarity in the behavior of the children in both situations. Both groups engaged in behaviors such as: copying, calling out answers, playing with clothes, chewing on pencils, and frowning. 
These behaviors were exhibited by low functioning as well as higher functioning children. The children exhibited the same behaviors regardless of socioeconomic background, race, and gender. The testing situations described in this paper did not appear to have a positive effect on any of the children. All of the children observed exhibited behaviors said to be stress related.

Each of the testing situations has implications for assessment of young children. Both of the teachers participating in the study exhibited a nurturing and positive environment in their classrooms. However, the children exhibited behaviors said to be indicators of stress.

Neither testing situation gave a true assessment of what the children were capable of doing. This supports the opinions of Charlesworth (1985) and Worthen (1990), who felt that this type of assessment does not give a true picture of the children mastery of the subject matter or match the instructional methods being used in the classroom. The children were forced to participate in a testing situation that was not congruent with the instructional practices that are used in their classrooms. In addition, they were not allowed to engage in behavior that was natural and positive to them, which included talking and helping their peers. To the children, copying and saying the answers aloud were not negative behaviors due to the instructional practices 
normally used in their classrooms. However, the copying and calling out answers were negative because the children had been instructed not to talk and to do their own work in accordance with the guidelines that accompanied the test. In light of this, the behavior of the children makes the practice inappropriate.

Three independent observers were asked to view the video tapes taken during the administration of the standardized achievement test. They were told to observe the children and then to describe their behavior. The word "stress" was never mentioned prior to the viewing of the tapes.

The first observer was a pediatrician who has treated young children for stress. She stated that many of the children whom she treats for stress can trace the stress back to situations at school that do not meet the children's needs. According to the pediatrician, "Sometimes the children are forced to change schools because the schools are not willing to change to meet the children's needs. They want the child to change to meet the school." After observing the tapes, she indicated that there were definite signs of anxiety being exhibited. She was especially concerned with Luke at Laurel Meadow. According to her, "You can actually see him falling apart. How can anyone think that this (the test) can show you what those children are capable of? That's just beyond me." 
When asked about the children who copied answers, she stated that she felt it was because they felt insecure but whether it was caused by home or school could not be determined by watching the tapes. What bothered her the most was that at ages five and six the children felt that they must have the right answer.

The second observer was a guidance counselor employed in a private school in a city outside the data collection area and the university where the research was coordinated. She also agreed that there were signs of anxiety being exhibited. She had some concerns about the validity of the test due to the copying and the calling out of answers. She said, "There is no way this can be considered a true picture of those children's capabilities." She also reported that several children seemed very anxious during the test.

The third observer was a family counselor in private practice. He was also concerned about the amount of movement (wiggling in the seat and shuffling of papers) exhibited by the children during the test, as well as the copying. He felt these were signs of insecurity. The observers had a variety of comments to make that reflected their particular training and points of view but all believed that there were definite indications of stress behavior exhibited.

The purpose of this study was to assess the stressrelated behaviors of kindergarten children during standardized achievement test-taking. The primary objective 
of the research was to assess whether the level of stress increased, decreased, or stayed the same during test taking situations. The literature has suggested that pencil and paper tests are not the best way to assess young children. The findings of this study seem to support this position. The children engaged in a number of behaviors said to be indicators of stress. These reported indicators of stress did increase during administration of a standardized achievement test and then decreased after the testing was complete. The behaviors exhibited by the children in this study are similar to those reported by Wodtke, Harper, Schommer, \& Brunelli (in press). The kindergarten children in the Wodtke et al. (in press) study were reportedted to engage in copying answers, calling out answers, and inattentive behavior (gazing around the room, humming and singing, talking, and generally restless behavior).

The levels of stress differed in the two schools in which the field work was conducted. The level of stress exhibited by the children at Laurel Meadow seemed to be greater than that at Woodmere. This could be attributed to the pressure placed on the teachers at Laurel Meadow to increase test scores and to the teacher having to engage in practices that are against her theoretical beliefs.

\section{Future Research}

The type of field work conducted in this dissertation 
allowed me to get an indepth look at kindergartners during standardized achievement testing. The findings indicate that more information is needed on the principal's impact on the testing situation. Interviews need to be conducted with all the teachers in the school to insure that the pressure felt is not an isolated incident. Also, due to the low number of low socioeconomic participants, the study should be repeated to see if this group's behavior is similar or different from the children observed during testing.

It is hoped that this research will provide the basis for suggesting alternative methods of assessing young children. Hopefully, alternative assessments would prove to be less stressful and more valid than standardized achievement tests. 


\section{References}

Bentley, S. (1988). The other half of the kindergarten day: A critical appraisal of stress levels in kindergarten students. Unpublished master's thesis, Oklahoma State University, Stillwater, OK.

Bereiter, C. (1986). Does direct instruction cause delinquency? Early Childhood Research Quarterly, 1, 289292.

Berliner, D., \& Tikunoff, W. (1977). Ethnography in the classroom. In G. Borich \& K. Fenton (Eds.), The Appraisal of teaching: Concepts and process (pp. 280-290). Reading, MA: Addison \& Wesley.

Bifano, S. L. (1987). Elementary principals: Espoused theory and professional practice. Unpublished doctoral dissertation, Texas A \& M University, College Station, TX.

Bracey, G. W. (1986). Mismatch of testing and instruction is pervasive. Phi Delta Kappan, 67(7), 534-535.

Bredekamp, S. (Eds.). (1987). Developmentally appropriate practice in early childhood programs serving children from birth through age 8. Washington D.C.: National Association for the Education of Young Children.

Bredekamp, S., \& Shepard, L. (1989). How best to protect children from inappropriate school expectations, practices, and policies. Young Children, $44(3), 14-24$. Brophy, B. (1986, October 27). Children under stress. U.S. News \& World Report, pp. 58-64. 
Burts, D. C., Hart, C. H., Charlesworth, R., \& Kirk, L. (in press). A comparison of frequencies of stress behaviors observed in kindergarten children in classrooms with developmentally appropriate vs. developmentally inappropriate instructional practices. Early Childhood Research Quarterly.

Charlesworth, R. (1985). Readiness: Should we make them ready or let them bloom? Day Care and Early Education, 12, $25-27$.

Charlesworth, R. (1987). Understanding child development. Albany, NY: Delmar Publishers Inc.

Charlesworth, R. (1989). "Behind before" they start? Deciding how to deal with the risk of kindergarten failure. Young Children, $\underline{44}(3), 5-13$.

Charlesworth, R., Hart, C. H., Burts, D. C., \& Hernandez, S. (1989). Kindergarten teachers' beliefs and practices. Manuscript submitted for publication.

Choen, R. A. (1969). Conceptual styles, culture conflict, and nonverbal tests of intelligence. American Anthropologist, $\underline{71}(5), 828-856$.

Conne11, D. R. (1987). The first 30 years were the fairest: Notes from the kindergarten and ungraded primary $(K-1-2)$. Young Children, $42(5), 30-39$.

Cryan, J. R. (1986). Evaluation: Plague or promise? Childhood Education, 62(5), 344-350.

Devaney, K. (1974). Evaluating children's growth. In Open 
Education in American. Washington, D.C.: National Association for the Education of Young Children.

Dickinson, D. K., \& Snow, C. E. (1987). Interrelationships among prereading and oral language skills in kindergartners from two social classes. Early Childhood Research Quarterly, $\underline{2}, 1-25$.

Durkin, D. (1987). A classroom observation study of reading instruction in kindergarten. Early Childhood Research Quarterly, $\underline{2}, 275-300$.

Staff. (1989, Fall). Testing, tracking, \& timing:

Challenging policies that deny equity and access to young children. The Early Childhood Advocate, pp. 1, 4 .

Elkind, D. (1981). The hurried child. Needham, MA: AddisonWesley.

Elkind, D. (1986). Formal education and early childhood education: An essential difference. Phi Delta Kappan, $\underline{67}(9), 631-636$

Elkind, D. (1988). Miseducation: Preschoolers at risk. New York, NY: Alfred A. Knopf.

Elkind, D. (1989). Developmentally appropriate practice: Philosophical and practical implications. Phi Delta Kappan, $71(2), 113-117$.

Farr, R., \& Carey, R. F. (1986). Reading: What can be measured? (2nd ed.). Newark, DE: International Reading Association.

Flood, J. M. \& Lapp, D. (1987). Types of writing in basal 
readers and assessment tests: An imperfect match. The Reading Teacher, $\underline{40}(9), 880-883$.

Fuqua, J. D. (1986). Teacher management practices and kindergarten children's perception of positive classroom climate. Unpublished doctoral dissertation, Texas A \& M University, College Station, TX.

Gallagher, J. M., \& Coche, J. (1987). Hothousing: The clinical and educational concerns over pressuring young children. Early Childhood Research Quarterly, 2, 203-210.

Gersten, R. (1986). Response to "Consequences of three preschool curriculum models through age 15." Early Childhood Research Quarterly, 1, 293-302.

Glaser, B. G., \& Strauss, A. L. (1967). The discovery of grounded theory: Strategies for qualitative research. Chicago, IL: Aldine Publishing Co.

Glicking, E. E., \& Thompson, V. P. (1985). A personal view of curriculum-based assessment. Exceptional Children, $\underline{52}(3), \quad 205-218$.

Gredler, G. R. (1978). A look at some important factors in assessing readiness for school. Journal of Learning Disabilities, $\underline{11}(5), 25-31$.

Gredler, G. R. (1984). Transition classes: A viable alternative for the at-risk child? Psychology in the Schools, $\underline{21}(4) 436-470$.

Haney, W., \& Madaus, G. (1989). Searching for alternatives to standardized tests: Whys, whats, and whithers. Phi 
De1ta Kappan, $\underline{70}(9), 683-687$.

Hatch, J. A., \& Freeman, E. B. (1988). Kindergarten philosophies and practices: Perspectives of teachers, principals, and supervisors. Early Childhood Research Quarterly, $3,151-166$.

Hiebart, E. H. (1988). The role of literacy experience in early childhood programs. The Elementary School Journal. $\underline{89}(2), 161-171$.

Hirsh-Pasek, K., \& Cone, J. (1989, April). Hurrying children: How does it affect their academic, social, creative, and emotional development? Paper presented at the biennial meeting of the Society for Research in Child Development, Kansas City, MO.

Hollingshead, A. B. (1975). Four factor index of social status. Unpublished manuscript, Yale University, New Haven, CT.

Honig, A. S. (1986a). Stress and coping in children (Part 1). Young Children, $41(4), 50-63$.

Honig, A. S. (1986b). Stress and coping in children (Part 2): Interpersonal family relationships. Young Children. $\underline{41}(5), \quad 47-59$.

Hoy, W. K., \& Clover, S. I. (1986). Elementary school climate: A revision of the OCDQ. Educational Administration Quarterly, 22(1), 93-110.

Hyson, M. (1988, November). Can NAEYC'S "Guidelines for developmentally appropriate teaching practices" be 
operationalized and developed into a reliable observation instrument? Paper presented at the preconference sessions for the meeting of the National Association for the Education of Young Children, Anaheim, CA. Isenberg, J. (1987). Societal influences on children. Childhood Education, 63, 241-342.

Jensen, M. , \& Chevalier, Z . (1988, November). Can early childhood teacher education students use NAEYC's developmentally appropriate practice guidelines to analyze observed or described curriculum practices? Paper presented at the preconference sessions for the meeting of the National Association for the Education of Young Children, Anaheim, CA.

Kamii, C. (1985). Leading primary education toward excellence: Beyond worksheets and drills. Young Children. $\underline{40}(6), 3-9$.

Karweit, N. (1988). A research study: Effective preprimary programs and practices. Principal, $\underline{6}(5), 18-21$.

Labinowicz, E. (1980). The Piaget primer. Menlo Park, CA: Addison-Wesley.

Laosa, L. M. (1977a). Nonbiased assessment of children's abilities: Historical antecedents and current issues. In T. Oakland (Ed.), Psychological and Educational Assessment of Minority Children. New York, NY: Brunner/Mazel. Laosa, L. M. (1977b). Socialization, education and continuity: The importance of the sociocultural context. 
Young Children, 32(5), 21-27.

Lincoln, Y. S., \& Guba, E. G. (1985). Naturalistic inquiry.

Beverly Hills, CA: Sage Publications.

Madaus, G. F. (1988). The influence of testing on the curriculum. In L. N. Tanner (Ed.), Critical issues in curriculum (pp. 83-121). Chicago, IL: The National Society for the Study of Education.

McCracken, J. B. (1986). Reducing stress in young children's lives. Washington, D. C.: National Association for the Education of Young Children.

Meisels, S. J. (1987). Uses and abuses of developmental screening and school readiness testing. Young Children. 42(2), 4-9. Meisels, S. J. (1989). High stakes testing in kindergarten. Educational Leadership, $\underline{46}(7), 16-22$.

Mendelson, A., \& Atlas, R. (1973). Early childhood assessment: Paper and pencil for whom? In Reading in early childhood education 77/78. Guilford: Dushkin Publishing Group, Inc., 269-271.

Miller, P. H. (1983). Theories of developmental psychology. New York, NY: W. H. Freeman \& Co.

Montessori, M. (1964). The Montessori method. New York, NY: Schocken. (Original work published in 1912.)

Morado, C. (1987, April). Kindergarten alternatives for the child who is "not ready": Programs and policies. Paper presented at the meeting of the Society for Research in Child Development, Baltimore, MD. 
NAEYC position statement on standardized testing of young children 3 through 8 years of age (1988). Young Children, $\underline{43}(3), 42-47$.

Nei11, D. M., \& Medina N. J. (1989). Standardized testing: Harmful to educational health. Phi Delta Kappan, $\underline{70}$ (9), $688-697$.

O'Brien, S. J. (1988). Childhood stress: A creeping phenomenon. Childhood Education, 65(2), 105-106.

Olson, L. (1987). Districts turn to nonprofit group for help in "Realigning" curricula to parallel tests. Education Week, $\underline{7}(8), 1,19$.

Perrone, V. (1981). Testing, testing and more testing. Childhood Education, 51, 76-80.

Piaget, J. (1950). The psychology of intelligence (M. Piercy \& D. Berlyne, Trans.). London: Routledge \& Kegan Paul LTD. (Original work published 1947)

Piaget, J. (1952). The origins of intelligence in children (M. Cook, Trans). New York: W. W. Norton \& Co., Inc. Piaget, J. (1970). Science of education and the psychology of the child (D. Coltman, Trans.). New York: Viking Press. (Original work published 1969)

Piaget, J., \& Inhelder, B. (1969). The psychology of the child (H. Weaver, Trans.). New York: Basic Books, Inc. (Original work published 1966)

Popham, W. J. (1988). Educational evaluation. Englewood Cliffs, NJ: Prentice Hall. 
Rutter, M. (1979a). Maternal deprivation, 1972-1978: New findings, new concepts, new approaches. Child Development, $\underline{50}, 283-305$.

Rutter, M. (1979b). Protective factors in children's responses to stress and disadvantage. In M. W. Kent \& J. E. Rolf (Eds.) Primary prevention of psychopathology. Volume III: Social competence in children (pp. 49-74). Hanover, NH: University Press of New England.

Schweinhart, L. J., Weikart, D. P., \& Larner, M. (1986). Consequences of three preschool curriculum models through age 15. Early childhood Research Quarterly, 1, 15-45.

Selye, H. (1976). The stress of life (rev. ed.). New York. NY: McGraw-Hil1.

Shepard, L. A., \& Smith M. L. (1986). Synthesis of research on school readiness and kindergarten retention.

Educational Leadership, $\underline{44}(3), 78-86$.

Shepard, L. A., \& Smith M. L. (1987). Effects of kindergarten retention at the end of first grade. Psychology in the Schools, 24, 346-357.

Shepard, L. A., \& Smith M. L. (1988). Escalating academic demand in kindergarten: Counterproductive policies. The Elementary School Journal, 89(2), 135-145.

Short, V. M. (1988). President's message: The curriculum "flunks" the test. ACEI Exchange, 56 (6), 3 .

Sigel, I. E. (1987). Does hothousing rob children of their childhood? Early Childhood Research Quarterly, 2, 211- 
225.

Skinner, B. F. (1968). The technology of teaching. New York: Appleton-Century-Crofts.

Smith, M. L., \& Shepard, L. A. (1987). What doesn't work:

Explaining policies of retention in the early grades. Phi Delta Kappan, $\underline{69}(2), 129-134$.

Smith, M. L., \& Shepard, L. A. (1988). Kindergarten readiness and retention: A qualitative study of teachers' beliefs and practices. American Educational Research

Journal, 25(3), 307-333.

Swick, K. (1987). Managing classroom stress. Dimensions, $\underline{15}(4), 9-11$.

Teale, W. H., Hiebart, E. H., \& Chittenden, E. A. (1987). Assessing young children's literacy development. The Reading Teacher, $\underline{40}(8), 772-777$.

Testing: Is there a right answer? (1988, Sept/Oct.). The Harvard Education Letter, $\underline{4}(5), 1-4$.

Torrance, E. P. (1974). Assessment of disadvantaged minority group children. Educational Horizons, 52(4), 197-201.

Travers, J. R. (1982). Testing in educational placement:

Issues and evidence. In K. A. Holtzman \& S. Messick (Ed.), Placing children in special education: A strategy for equity (pp. 230-261). Washington, D. C.: National Academy Press.

Valencia, S., \& Pearson, P. D. (1987). Reading assessment: Time for a change. The Reading Teacher, 40(8), 726-732. 
Walsh, D. J. (1989). Changes in kindergarten: Why here? Why now? Early Childhood Research Quarterly, 4(3), 377-391.

Willert, M. K., \& Kamii, C. (1985). Reading in kindergarten: Direct vs. indirect teaching. Young Children, $\underline{40}(4), 3-9$. Williams, C. K., \& Kamii, C. (1986). How do children learn by handling objects? Young Children, $\underline{42}(1), 23-26$.

Wodtke, K. H., Harper, F., Schommer, M. \& B Bunel1i, P. (in press). How standardized is school testing? An exploratory observational study of standardized group testing in kindergarten. Educational Evaluation and Policy Analysis. Wortham, S. C. (1990). Tests and measurement in early childhood education. Columbus, OH: Merrill. 
APPENDIX A

TEACHER QUESTIONNAIRE 
TEACHER QUESTIONNAIRE

\begin{abstract}
Name
(Confidentiality of the respondent is guaranteed. Names of respondents nor schools will not be used in any reporting of the findings from this study.)

Highest Degree Earned

Year of Graduation

Name of College or University

Name of this School

Is this school public, private, or parochial?

Is this kindergarten developmental* or regular?

How many years have you taught Kindergarten?

How many years have you taught in this school?

How many years have you taught in other schools?

Number of children in classroom

*Gesell is used to determine 'regular' or 'developmental' placement.
\end{abstract}

Developed by Sue Hernandez, Lisa Kirk, Craig Hart, Diane Burts, \& Rosalind Charlesworth, Louisiana State Uni.

For information write: Dr. Rosalind Charlesworth, LSU

College of Education, Baton Rouge, LA 70803. (504) 388-2443. 


\section{TEACHER BELIEFS SCALE}

1. Rank the following $(1-6)$ by the amount of influence you feel that each has on the way you plan and implement instruction. (Please be sure to use each number only once. $1=$ Most influence; $6=$ least influence).

Parents

Parish or school system policy Principal

Teacher (yourself)

State regulations

Other teachers

Please respond to the following items by circling the number that most nearly represents YOUR PERSONAL BELIEFS about the importance of that item in a kindergarten program.

$\begin{array}{ccccc}1 & 2 & 3 & 4 & 5 \\ \text { Not } & \text { Not } & \text { Fairly } & \text { very } & \text { extremely } \\ \text { important } & \text { very } & \text { important } & \text { important important } \\ \text { at all } & \text { important } & & \end{array}$

2. As an evaluation technique in the kindergarten program, standardized group tests are

3. As an evaluation technique in the kindergarten program, teacher observation is _...... 12345

4. As an evaluation technique in the kindergarten program, performance on worksheets and workbooks is

5. It is_._._for kindergarten activities to be responsive to individual differences in interest.

6. It is_._. for kindergarten activities to be responsive to individual differences in development.

7. It is _._that each curriculum area be taught as separate subjects at separate times.

8. It is___for teacher-pupil interactions in kindergarten to help develop children's selfesteem and positive feelings toward learning.

9. It is for children to be allowed to select many of their own activities from a variety of learning areas that the teacher has prepared. 
10. It is _._for children to be allowed to cut their own shapes, perform their own steps in an experiment, and plan their own creative drama, art, and writing activities.

11. It is__._ for students to work silently and alone on seatwork.

12. It is_._. for kindergartners to learn through active exploration.

13. It is _._for kindergartners to learn through interaction with other children.

14. Workbooks and/or ditto sheets are _._.- to the kindergarten program.

15. Flashcards (numbers, letters, and/or words) are to the kindergarten program for instructional purposes.

16. The basal reader is to the kindergarten reading program.

17. In terms of effectiveness, it is__.for the teacher to talk to the whole group and make sure everyone participates in the same activity.

18. In terms of effectiveness, it is _.._for the teacher to move among the groups and individuals, offering suggestions, asking questions, and facilitating children's involvement with materials and activities.

19. It is _._for teachers to use their authority through treats, stickers, and/or stars to encourage appropriate behavior.

20. It is _for teachers to use their authority through punishments and/or reprimands to encourage appropriate behavior.

21. It is for children to be involved in establishing rules for the classroom.

22. It is_._. for the children to be instructed in recognizing the single letters of the alphabet, isolated from words.

23. It is _.. for children to color within predefined lines.

24. It is _._for children in kindergarten 
to form letters correctly on a printed line. $\begin{array}{rrrrr}1 & 2 & 3 & 4\end{array}$

25. It is _._for children to have stories read to them individually and/or on a group basis.

26. It is_._. for children to dictate stories to the teacher.

27. It is_._. for the children to see and use functional print (telephone books, magazines, ect.) and environmental print (cereal boxes. potato chip bags, etc.) in the kindergarten classroom.

28. It is _._for the children to participate in dramatic play.

29. It is for children to talk informally with aduits.

30. It is__for the children to experiment with writing by inventing their own spelling.

31. It is _.. to provide many opportunities to develop social skills with peers in the classroom.

32. It is___for kindergartners to learn to read.

33. In the kindergarten program, it is that math be integrated with all other curriculum areas.

34. In teaching health and safety, it is...to include a variety of activities throughout the year.

35. In the classroom setting, it is for for the child to be exposed to multicultural and nonsexist activities.

36. It is _._that outdoor time have planned activities.

$\begin{array}{lllll}1 & 2 & 3 & 4 & 5\end{array}$

37. Input from parents is

$\begin{array}{lllll}1 & 2 & 3 & 4 & 5\end{array}$ 


\section{INSTRUCTIONAL ACTIVITIES SCALE}

Please respond to the following items by circling the number that most nearly represents how of ten your children participate in the following activities, on the average.

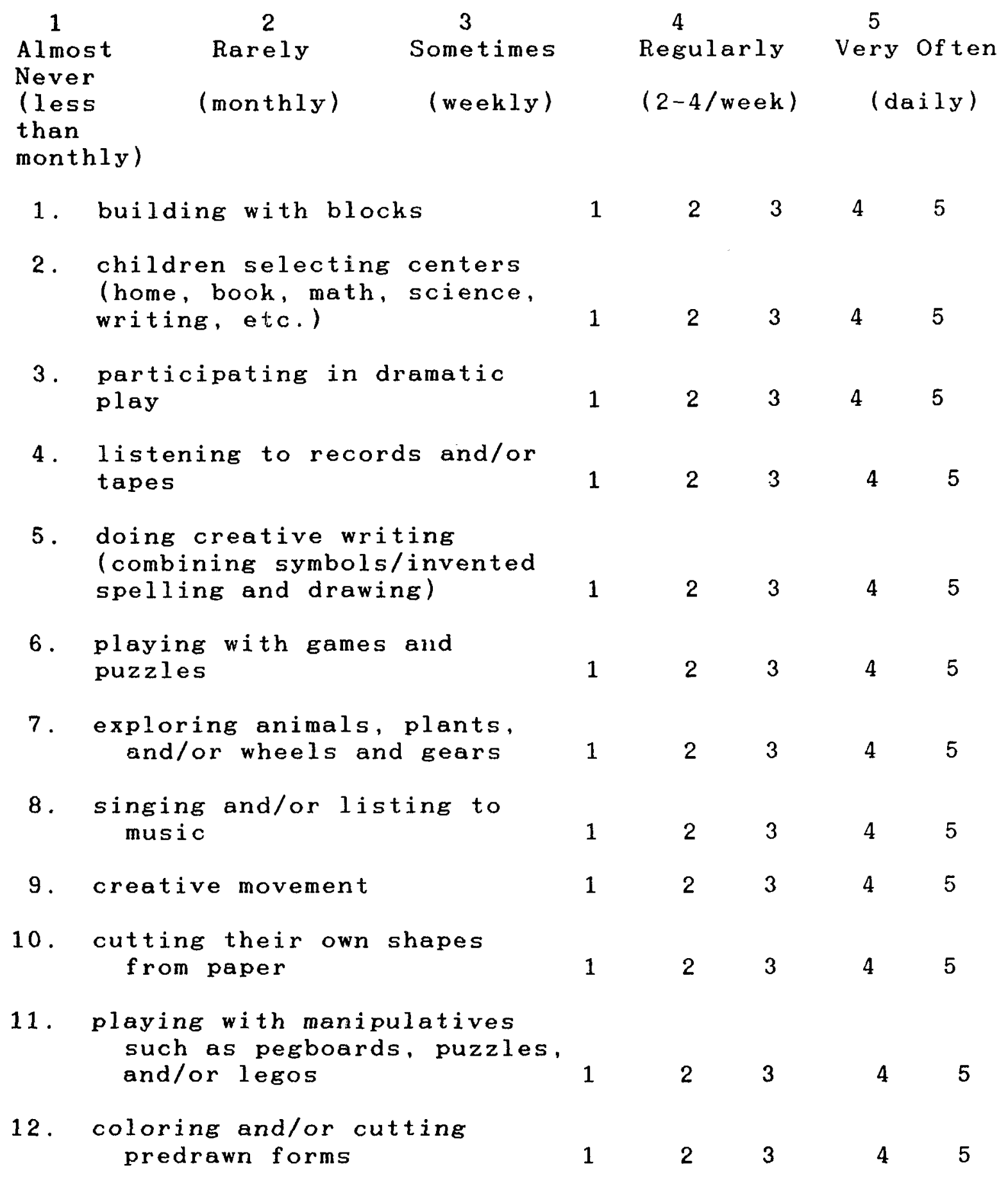


13. children reading in ability level groups

14. circling, underlining, and/or marking on items on worksheets

$\begin{array}{lllll}1 & 2 & 3 & 4 & 5\end{array}$

15. using flashcards with sight words and/or math facts

$\begin{array}{lllll}1 & 2 & 3 & 4 & 5\end{array}$

16. rote counting

2

3

5

17. practicing handwriting on 1 ines

18. reciting the alphabet

1

19. copying from the chalkboard

20. sitting for longer than

15 minutes

1

23

4

5

21. waiting for longer than

5 minutes between activities

1

23

5

22. large group teacher directed instruction

23. children coordinating their own activities in centers

24. tangible rewards for appropriate behavior and/or performance

25. losing special privileges

(trips, recess, free time, parties, etc.) for

misbehavior

26. social reinforcement (verbal praise, approval, attention, etc.l for appropriate behavior and/or performance 1

27. using isolation (standing in

the corner or outside of the room) to obtain child 
28. games/activities directed

$\begin{array}{lllllll}\text { by or made by parents } & 1 & 2 & 3 & 4 & 5\end{array}$

29. specifically planned

outdoor activities

30. multicultural and nonsexist

activities

$\begin{array}{lllll}1 & 2 & 3 & 4 & 5\end{array}$

31. competitive math activities

to learn math facts

1

23

4

5

32. health and safety activities

2

5

33. drawing, painting, working with playdough, and other art media

3

4

5

34. math incorporated with other subject areas

$\begin{array}{llll}1 & 2 & 3 & 4\end{array}$

5 
APPENDIX B

CHECKLIST FOR RATING DEVELOPMENTALLY APPROPRIATE PRACTICE IN KINDERGARTEN CLASSROOMS 


\section{CHECKLIST FOR RATING DEVELOPMENTALLY APPROPRIATE PRACTICE IN KINDERGARTEN CLASSROOMS}

Based on S. Bredekamp (Ed.) (1987) Developmentally appropriate practice in early childhood programs serving children from birth through age eight (exp. ed.). Washington, D.C.: National Association for the Education of Young Children. Section on the Primary Grades, ages 5-8.

School Principal

Teacher Ages of Children

Number of Children in room Number of adults

Observed/rated by

Date

Time

Activity/Activities

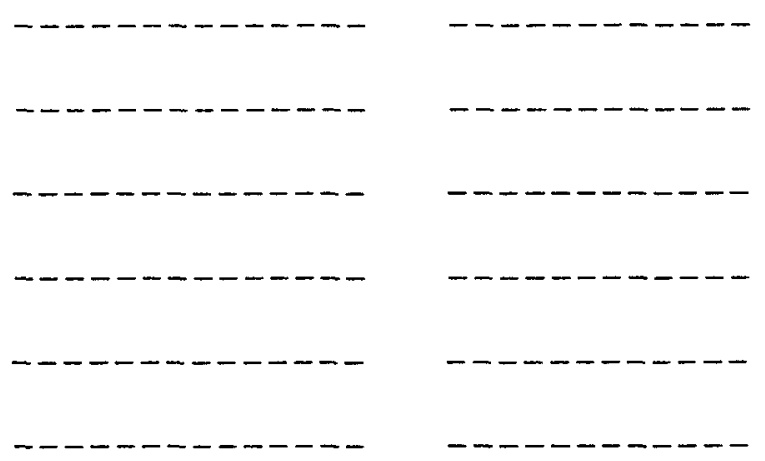

Five points are listed for rating each item. Under 5 the most appropriate practice indicators are listed, under point 1 the most inappropriate indicators are listed. Point 5 indicates close to $100 \%$ appropriate, point 4 indicates more appropriate than inappropriate. Point 3 indicates a fairly even split between appropriate and inappropriate. Point 2 indicates more inappropriate than appropriate. Point 1 indicates close to $100 \%$ inappropriate. Below each item there is a space for a brief description of what you observed or found out by questioning the teacher that underlies your rating.

Developed by Rosalind Charlesworth, Jean Mosley, Diane Burts, Craig Hart, Lisa Kirk, and Sue Hernandez, Louisiana State University, Baton Rouge. 
Curriculum Goals

1. Range of Curriculum Areas for Which Program is Designed 5 4

3

2

1

.physical

. social

. emotional

intellectual

. learning how to learn

.narrow focus

- intellectual emphasis . discrete academic skills emphasis

Description:

2. The Place of Children's Self-esteem, Sense of

Competence, and Positive Feelings Toward Learning in the Curriculum and Instruction.

5

4

3

2

1

. Each child is given an

. Children who conform equal amount of positive receive more attention attention

. Children are given attention according to their level of academic performance

Description:

3. View of Growth and Development.

5 4 3 2 1

. individualized

. Children move at their own pace

. Evaluated against a group norm

- Everyone is expected to achieve the same narrowly defined skills

- Everyone does the same thing at the same time

Description: 
TEACHING STRATEGIES

4. The Emphases in the Curriculum.

43

3

2

1

. Learning occurs through

through projects and

learning centers

. Children's ideas

are extended, questions

are encouraged, and

interests are developed

. All subjects are integrated

into units

. Curriculum is divided into discrete subject and time units

. Emphasis on reading

first and math second

. Social studies, science, health are included only if time permits

-Art, music, and physical education are taught once

a week by specialists

Description:

5. Organization of the Curriculum.

$4 \quad 3$

2

1

Activities center on topics such as in science or social studies

. Topic activities include story writing and story telling, drawing, discussion, hearing stories and informational books, and cooperative activities

Skills are taught as they are needed to complete a task

. Teacher directed reading groups

Lecturing to the whole group

. Paper and pencil

exercises, workbooks, worksheets

Projects, leerning centers, and play are offered only if time permits or as a reward for completing work

Description: 
6. Teacher Preparation and Organization for Instruction.

5

. Learning centers are set up which provide opportunities for writing, reading, math and language games, dramatic play

. Children are encouraged to critique their own work

. Errors are viewed as normal and something from which children can learn

Description:

7. Instructional Activities.

5

4

3

. Children work and play cooperatively in groups

. Projects are self selected with teacher guidance

. Activity centers are changed frequently

. One or more field trips

. Resource people visit

. Peer tutoring

- Peer conversation

Description:
2

1
. Little time for enrichment activities May be interest centers available for children who finish their seatwork - May be centers where children complete a prescribed sequence of teacher-directed activities within a controlled time period
$2 \quad 1$

. Children work alone, silently on their worksheets or workbooks . Little, if any, peer help is permitted .Penalties for talking 
8. Learning Materials and Activities.

5 4

3

2

1

- Concrete, real, and relevant

. Limited primarily to to children's lives

. Blocks, cards, games, arts. and crait materials, woodworking tools, science equipment, etc.

. Flexible work spaces (tables carpet, etc.)

workbooks, and pencils

- Permanent desks that are rarely moved

. Mostly large group instruction

. Playful activity only when work is done

Description:

INTEGRATED CURR I CULUM

Note: If you reach the end of your observations and any areas cannot be rated due to lack of information, arrange to meet with the teacher and ask the opened-ended clarification questions. Use the descriptors as probes if necessary.

9. Language and Literacy.

5

43

2

1

Technical skills are taught as needed

Generous amounts of time are provided to learn through literature and nonfiction reading; drawing, dictating, and writing stories;

bookmaking; and library visits

. Daily reading aloud by teacher

. Subskills such as letters and phonics are taught individually and in small groups using games . Literacy is taught through content areas such as science and social studies . Children' invented spellings are accepted

Teaching is geared to passing standardized tests

- Reading taught through skills and subskills

. Reading taught as a discrete subject

Silence is required

. Language, writing, and spelling instruction focus on workbooks . Teaching focuses on reading groups with other children having an adequate amount of seatwork to keep busy . Phonics instruction stresses learning rules rather than relationships Everyone must complete the same basals no matter what their abilities 
. Everyone knows who is in the slowest reading group Acceptable writing has correct spelling and is standard English

Description:

(Clarification: Describe your language and literacy program.)

10. Math

5

$4 \quad 3$

2

1

. Children encoliraged to use math through exploration, discovery, and solving meaningful problems - Integrated with other areas . Skills acquired through play, projects, and daily living manipulatives are used . Math games used daily

- Taught as a separate subject

. Taught as a scheduled time each day . Focus on textbook, workbook, practice sheets board work

. Lessons follow text . Math sequence

. Seldom any "hands on" activity

. Must finish work in order to use games and manipulatives

Description:

(Clarification: Describe your math program.)

11. Social Studies.

5 4 3 2 1

. Themes may extend over a . Included occasionally period of time

. Learned through playful if reading and math activities, discussion, trips, visitors, writing, reading, social skills development, (planning, sharing, taking turns) are completed

. Mostly related to holidays

Brief activities from the social studies textbook or commercially 
Art, music, dance, drama, woodworking, and games are incorporated developed newspaper (i.e. Weekly Reader) and doing dittoed seatwork

Description:

(Clarification: Describe your social studies program.)

12. Science.

5 4 3 2 1

. Discovery, built on the children's natural interest in the world

Projects are experimental and exploratory, encourage active involvement of each child

. Plants and pets in the classroom

. Through projects and field trips children learn to plan, apply thinking skills, hypothesize, observe, experiement, verify

. Learn science facts related to their own experience

Description:

(Clarification: Describe your science program.)

. Taught from a single textbook or not at all

- Complete worksheets

. Watch teacher demonstrations

. No field trips - Materials in the science center are rarely changed

13. Health and Safety.

- Projects designed to help children use personalized facts

. They learn to integrate facts into their daily habits

. Dictate or write their own plans

. Draw or write about these activities

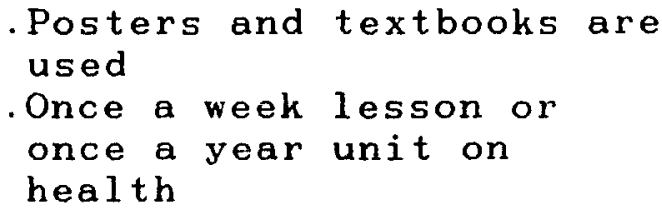


. Read about these activities

. Enjoy learning because it is

related to their lives

Description:

(Clarification: Describe you health and safety curriculum.)

14. Art, Music, Movement, Woodworking, Drama, and Dance.

5

4

3

2

1

. Integrated throughout

the day

Specialists work with

teacher and children

. Children explore a variety art media and music

. Children design and direct

their own products and

productions

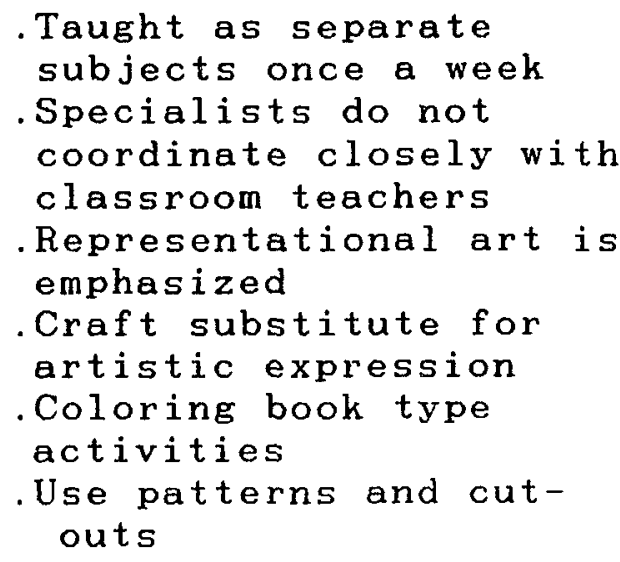

Description:

(Clarification: Tell me about your program in the arts; such as art, music, movement, woodworking, drama, and dance.)

15. Multicultural Education

5

43

2

1

. Materials and activities

Material and activities

are multicultural and

nonsexist

lack evidence of

attention to cultural

diversity and a nonsexist

point of view

Description:

(Clarification: Tell me how you provide for multicultural education in your classroom.) 
16. Outdoor Activity.

5 $4 \quad 3$

2 1

. Planned daily so children can develop large muscle learn about outdoor environments, and express themselves freely on a well designed playground

. Limited because it interferes with skills, instructional time or -Provided as a time for recess to use up excess energy

Description:

(Clarification: Describe the focus of your outdoor activity program.)

GUIDANCE OF SOCIAL-EMOTIONAL DEVELOPMENT

17. Prosocial Behavior, Perseverance, and Industry

5

4

3

2

1

Stimulating, motivating activities are provided

Lectures about the that promote, student involvement

. Individual choices are encouraged

. Enough time is allowed to complete work

. Private time with friend or teacher is provided

importance of

appropriate social

behavior

. Punishes children who

become bored and restless with seatwork and

whisper, talk, or wander around

-Punishes children who do not finish work in allotted time

. No time for private conversations

. Only the most able students finish their work in time for special interests or interaction with other students.

Description: 
18. Help, Cooperating, Negotiating, and Solving Social Problems.

5

4

3

2

1

Daily opportunities to develop
social skills such as helping
others, cooperating, negotiating
and talking with others to solve
problems

. Little time to develop social skills--mostly independent seatwork and

teacher directed

activities

Only social opportunity is on the playground but no consistent adult is available to provide guidance

Description:

19. Guidance Techniques.

5

43

2

1

. Positive guidance techniques are used

-Clear limits are set in a positive manner

- Children involved in

establishing rules

-Children involved in

problem solving behavior

-Redirection is used

- Meets with the Child who has problems (and with parents)

-Recognize that every infraction doesn't warrant attention and identifies those that can be used as learning opportunities

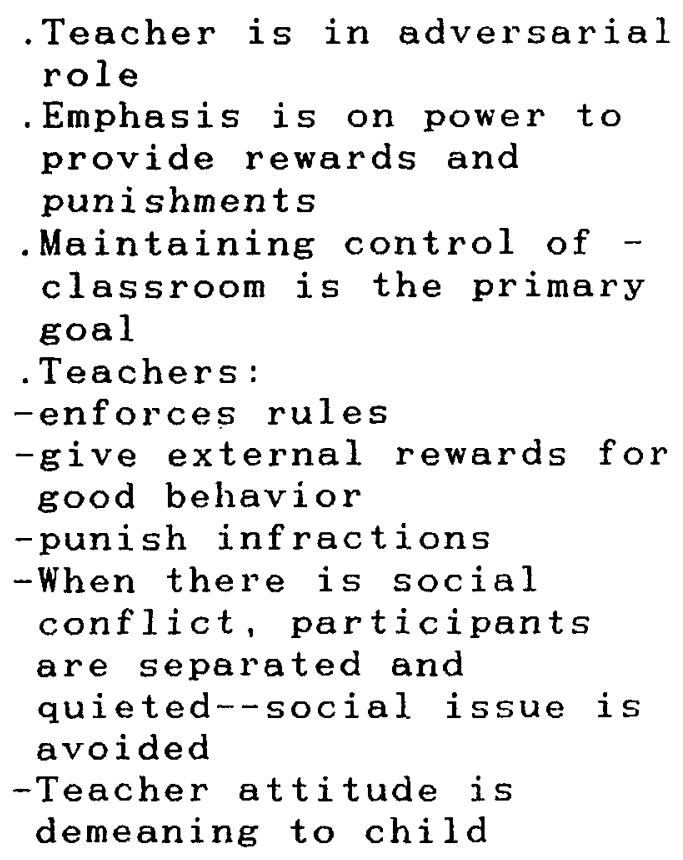

Description: 
20. Facilitation of self esteem by expressing respect, acceptance, and comfort for children regardless of their behavior.

5

4

3

21

. Children are trusted to make some of their own decisions

. Children are encouraged to

develop their own self control

Teacher is warm and accepting

. Teacher provides understanding and nurturance

. Teacher adapts to children's needs

. Teacher screams in anger

. Teacher neglects

children's individual

needs

. Physical or emotional

pain is inflicted

.Criticizes, ridicules,

blames, teases, insults, name-calls, threatens, frightens, and/or humiliates

. Laughs at the children in a derogatory manner

Description:

\section{MOTIVATION}

21. Internal vs. External Sources of Motivation and Rewards for Achievement.

5

4

3

2

1

. Encourages development of internal rewards and

internal critique

Guide children to see

alternatives, improvements and solutions

. Guide children to find and correct own errors

. Uses external rewards and punishments

. Corrects errors; makes sure children know right answers

- Rewards children with stickers, praises in front of group

Description:

22. Teacher as a Model for Motivation.

5 4 3

2 1

. Through relationship with . Children identify with 
teacher, child models teacher's enthusiasm for learning, identifies with teacher's conscientious attitude toward work, and gains in self motivation

Description:

\section{TRANSITIONS}

23. Transition Within School.

5

4

3

. Children are assisted in making smooth transitions between

groups or programs

Description:

24. Transitions Within Classroom 5 4 3

. Transition activities (i.e. special song)

-warning signals are given

ample time is allowed activity is intrinsically enticing

Descriptions: teacher's lack of enthusiasm and interest in his or her work and emulate it
$2 \quad 1$

. Day is fragmented among among many different groups and programs 
PARENT-TEACHER RELATIONS : INTERVIEW

25. Teacher's View of Parents.

4

3

2

1

- Parents as partners

- Periodic conferences are held

. Teachers not given adequate time to work

. Parents are welcome at school

Subtle messages make

. Home visits by teachers are encouraged

. Teacher listens to parents and respects their goals for the child, their culture and parents feel unwelcome at school

. Parents' role is to carry their family configuration

Description:

26. Parent Involvement in the Classroom.

$4 \quad 3$

2

1

- Family members are encouraged Schedule is too tight to help in the classroom

Family members are encouraged to help outside the classroom (such as making materials)

to include parents

- Parent participation policy is not followed . Teacher's only contact with parents is attending formal PTA/PTO meetings

Description:

27. Evaluation Methods.

5

$4 \quad 3$

2

1

. Assessment through observation

- Regular testing on each and recording at regular intervals

- Results are used to improve and individualize instruction subject

- Graded tests sent home

. Teach to the test to ease children's stress

Description: 
28. Administrator is supportive of and knowledgeable regarding developmentally appropriate early education practices.

- Appropriate practices are supported

- Principal demonstrates understanding of child development and implications for appropriate practices

. Principal is willing to gain information regarding appropriate practices and to make changes if needed appropriate

Description:
- Principal has minimal if any knowledge of child development

-Principal does not value developmentally

appropriate practices

Principal is unwilling to let teachers modify program so it is developmentally 
APPENDIX C

MY CLASS INVENTORY

161 


\section{PLEASE NOTE}

Copyrighted materials in this document have not been filmed at the request of the author. They are available for consultation, however, in the author's university library.

$$
\begin{aligned}
& 162-163 \\
& 165-166 \\
& 168-177
\end{aligned}
$$

University Microfilms International 


\section{APPENDIX D}

ORGANIZATIONAL, CLIMATE DESCRIPTION QUESTIONNAIRE-RS 
APPENDIX E

INTERPERSONAL ACTION SURVEY FOR ELEMENTARY 


\section{APPENDIX $F$ \\ SUPERVISOR OF RESEARCH \& PROGRAMMING'S \\ LETTER TO PRINCIPALS}




\section{RESEARCH, EVALUATION, AND LONG RANGE PLANNING DEPARTMENT}

Sept. 6, 1988

Memo To: Elementary Principals

From : Supervisor of Research \& Programming

Subject: Research Study: Developmentally Appropriate Practices Study

We have been asked by Drs. Diane Burts, Rosalind Charlesworth, and Craig Hart of Louisiana State University to cooperate in a study involving the kindergarten program. Dr..-...- has reviewed the study and recommends that we cooperate. The results would provide information regarding developmentally appropriate instructional practices for young children which could be used in designing instructional activities.

The proposed procedure for conducting the study is attached. In general, a questionnaire will be administered to all kindergarten teachers in the Fall of 1988; based upon the analysis of the questionnaire data, there would be follow up observations in selected kindergarten classrooms.

The study is approved by this office with the following understandings:

1. The researchers will contact you prior to the beginning of the study.

2. If needed the researchers will obtain parental permission for the participating students.

3. Upon completion of the study, a report of the findings will be made available to the school system.

If you have any concerns about the study please contact me. 
APPENDIX G

RESEARCH OUTLINE FOR TEACHERS 
Pamela O. Fleege

$\mathrm{Ph}$. 767-5342 or 388-2443

1. The study will consist of: (a) observations, which will be video taped; interviews, which will be audio taped with the permission of those being interviewed. Those to be interviewed will be student, teachers, principals, and auxiliary personnel. Photographs will be taken of the school and classrooms. I will also need access to student documents and any other pertinent data about the students.

2. The study will begin with observations prior to testing and continue during the testing week and will finish with a week of observations after testing ends.

3. No names of individuals or schools will be used. Complete anonymity is assured.

Persons to contact if you have questions:

1. Dr. Diane Burts 388-2408

2. Dr. Rosalind Charlesworth 388-2443

3. Dr. Sandra Bifano 388-6829

Thank you very much for your participation and I look forward to working with you.

Sincerely,

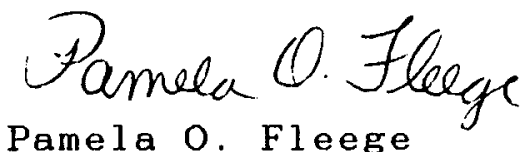

Pamela 0 . Fleege 
APPENDIX H

RESEARCH OUTLINE FOR PARENTS 
Apri1 4, 1989

Dear Parents,

I would like to thank you very much for allowing your child to participate in our research project. For the next several weeks I will be observing in your child's classroom and to help myself record what I observe I will be using a video camera. I will review the tapes at the end of the day to record any responses that I missed while in the classroom.

Again thank you for allowing your child to fis : it: in the study and if you have any questions pleasil ca: : 767-5342 or Dr. Sandra Bifano at $388-0.23$.

Sincerely,

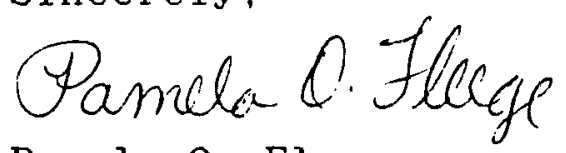

Pamela 0 . Fleege 


\section{VITAE}

Pamela O. Fleege

May, 1990

585 Jennifer Jean

Baton Rouge, La. 70808

I . DEGREES/EDUCATION

BS

Elementary Education

Uni. of Sou. MS. 1976

M. Ed.

Uni. of New Orleans 1985

Curriculum \& Instruction (Emphasis in Early Childhood Education/Minor Special Education)

Doctoral Candidate Louisiana State Uni. 1990 Curriculum \& Instruction (Emphasis in Early Childhood Education/Minor Education Administration)

\section{I. PROFESSIONAL EXPERIENCE}

A. Graduate Assistant, LSU Dept. of Curriculum \& Instruction (Stress Research Project)

B. University Teaching Louisiana State Uni. EDCI 4055 Principles and Practices in Kindergarten

Education Spring 1988 - Spring 1989

C. Public Schools Chapter I Preschool Teacher Orleans Parish Public Schools New Orleans, La. $1984-1987$

Kindergarten \& 1st Grade Teacher Jefferson Parish Public Schools Gretna, La. 1981 - 1984

2nd \& 3rd Grade Teacher Hancock County Public Schools Bay St. Louis, Ms. 1979 - 1981

3rd \& 6 th Grade Teacher Jefferson Parish Public Schools Gretna, La. 1977 - 1979

D. Private Schools 1st Grade Teacher Plaquemines Parish Independent Schools Belle Chasse, La. 1976 - 1977

\section{I . SCHOLARLY WORK}

A. Research/Writing Fleege, P. O. (1990). Stress begins in kindergarten: A look at behavior during standardized testing. Unpublished doctoral 
dissertation, Louisiana State University, Baton Rouge, LA.

Fleege, P. O., \& Charlesworth, R. (1990). What are the responsibilities of teacher educators relative to test reform? The Journal of Early Childhood Teacher Education, 11:1(34), 27-28.

Charlesworth, R., \& Fleege, P. O. (1989, June). Test reform and young children. LACUS Newsletter, 2pp. (La. Association on Children Under Six).

Fleege, P. O. (1990). Factors that Impede Successful Mainstreaming: An Ethnographic Study. Unpublished manuscript.

B. Presentations

(1990, April) (D. Burts, C. Hart, R. Charlesworth, R. Thomasson, P. Fleege, \& J. Mosley) Frequencies of Observed Stress Behaviors in Kindergarten Children: A Comparison of Developmentally Appropriate and Inappropriate Classrooms. Paper presented at the meeting of the American Education Research Association, Boston, MA.

(1990, March) (P. Fleege \& L. Kirk) QEEC--Quality Early Education Coalition: Developing A Model for Community Action By Creating an Awareness About Developmentally Appropriate Practices in Early Childhood Programs. Paper presented at the meeting of the Southern Association on Children Under Six, Dallas, TX.

(1989, November) (P. Fleege \& R. Charlesworth) Issues in Early Childhood Teacher Education: What Are the Responsibilities of Early Childhood Teacher Educators Relative to Test Reform. Paper presented at the meeting of the National Association of Early Childhood Teacher Educators, Atlanta, GA.

(1989, November) (P. Fleege \& R. Charlesworth) Roundtable Discussion on Test Reform: Why. How, When \& Who? Paper presented at the meeting of the Louisiana Association on Children Under Six. Alexandria, LA.

(1989, November) (P. Fleege \& L. Kirk) QEEC-Quality Early Education Coalition: Developing a Model for Community Action. Paper presented at the meeting of the Louisiana Association on Children Under Six, Alexandria, LA. 
Fleege, P. (1989, April). Visions for

Mainstreaming. Paper presented at the meeting of the Southern Association on Children Under Six. Richmond, VA.

Fleege, P. (1988, November). Mainstreaming: Do We Need Magic. Paper presented at the meeting of the Louisiena Association on Children Under Six, Monroe, LA.

C. Proposals Submitted Charlesworth, R., \& Fleege, P. (1990, November). Teaching Developmentally Appropriate Assessment in Early Childhood Teacher Education. To the meeting of the National Association of Early Childhood Teacher Educators.

Burts, D., Hart, C., Charlesworth, R., Fleege, P., Abshire, S., Campbel1, J., \& Durland, M. (1990, November). NAEYC'S Developmentally Appropriate Practice Guidelines: Research and Implications. To the meeting of the National Association for the Education of Young Children.

VI . PROFESSIONAL SERVICE AND MEMBERSHIP

Quality Early Education Coalition

Louisiana Association on Children Under Six

Louisiana Association for the Education of Young Children

Louisiana Association of Early Childhood Teacher Educators - Treasurer

Southern Association on Children Under Six

National Association for the Education of Young Children

National Association of Early Childhood Teacher Educators

American Educational Research Association 
DOCTORAL EXAMINATION AND DISSERTATION REPORT

Candidate: PAMELA OWEN FLEEgE

Major Field: EDUCATION

Title of Dissertation: STRESS BEGINS IN KINDERGARTEN = A LOOK AT BEHAVIOR DURING STANDARDIZED TESTING

Approved:

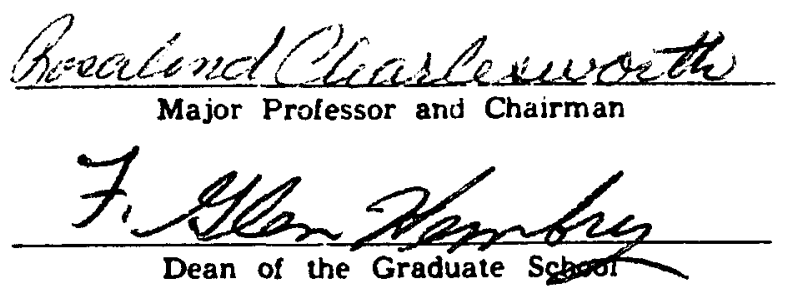

EXAMINING COMMITTEE:

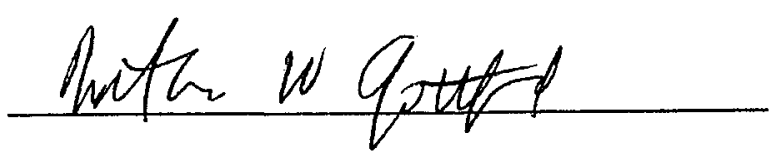

Craig H. Ho ut

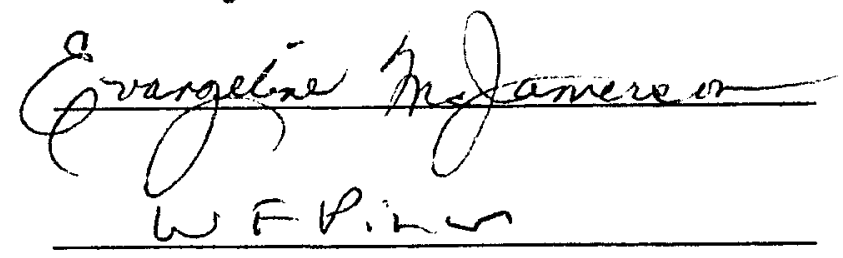

Mirin C Bur ts

Date of Examination:

Parch 27, 990 